\title{
Savings, intergenerational transfers, and the distribution of wealth
}

$\operatorname{AUTHOR}(\mathrm{S})$ :

Ponce Ocampo, Ignacio; Yuki, Kazuhiro

\section{CITATION:}

Ponce Ocampo, Ignacio ...[et al]. Savings, intergenerational transfers, and the distribution of wealth. 京都大学大学院経済学研究科Working Paper 2003, 68

ISSUE DATE:

2003-02

URL:

http://hdl.handle.net/2433/37947

RIGHT: 
Savings, Intergenerational Transfers, and the Distribution of Wealth

Ignacio Ponce Ocampo, Goldman Sachs, London and

Kazuhiro Yuki, Kyoto University

February, 2003

Graduate School of Economics

Faculty of Economics

Kyoto University

Kyoto, 606-8501 JAPAN 
Savings, Intergenerational Transfers, and the Distribution of Wealth

\author{
Ignacio Ponce Ocampo, Goldman Sachs, London \\ and
}

Kazuhiro Yuki, Kyoto University

February, 2003 


\title{
Savings, Intergenerational Transfers, and the Distribution of Wealth
}

\author{
Ignacio Ponce Ocampo and Kazuhiro Yuki *
}

August, 2002

\begin{abstract}
This paper investigates quantitative importance of different savings motives on wealth distribution and aggregate capital accumulation by solving an overlapping generations model with heterogeneity within generations. Agents differ in age, ability, earnings shocks and inherited bequests. In the baseline economy there are uninsurable idiosyncratic risks associated with uncertain lifetime and earnings shocks. The model is calibrated to the U.S. economy and solved numerically. Then we compare the allocations of the baseline economy with those of an economy with complete annuity markets, one without earnings uncertainty, and one without altruism. The numerical experiments show that different savings motives seem to affect savings behaviors of various parts of the population in an unequal manner. The effect of completing annuity markets is dominantly on the old population and results in a large increase in wealth and bequests inequality. Alternatively, taking out earnings uncertainty decreases savings by the young and poor, but lowers wealth inequality for the whole population. Finally, the disappearance of altruism affects mainly savings behaviors of the old and rich population, reducing wealth and bequests inequality. Regarding aggregate capital and bequests, aside from the pure life-cycle motive, altruism is the most important explaining factor. Secondly in order of importance, especially in explaining aggregate bequests, is the absence of annuity markets that generate precautionary savings among the retired population and accidental bequests. The absence of insurance markets for earnings uncertainty, which generates precautionary savings among the working population, seems to be least important, in particular, in explaining bequests accumulation.
\end{abstract}

*Ponce Ocampo: Goldman Sachs, London, UK; Phone ; E-mail Ignacio.Ponce-Ocampo@gs.com. Yuki: Faculty of Economics, Kyoto University, Yoshida-honmachi, Sakyo-ku, Kyoto, 606-8501, Japan; Phone +81-75-753-3532; E-mail yuki@econ.kyoto-u.ac.jp. The views expressed in this paper are those of the authors and do not reflect the official position of Goldman Sachs. We would like to thank Mark Bils and Hugo Hopenhayn for their continuous advice. Useful comments are also provided by Per Krusell. All errors are ours. 


\section{Introduction}

People save for many different reasons. Facing hump-shaped age-earnings profiles and no earnings after retirement, they save in order to smooth consumption over time, which can be called the life-cycle motive of savings. They face uncertain earnings and incomplete insurance markets, so they accumulate wealth in order to self-insure against such uncertainty (the precautionary motive of savings). Further, they save in order to leave bequests to their children since they derive utility from such behavior (the altruistic motive of savings). Finally, uncertain lifetime and incompleteness of annuity markets leave some portion of wealth intended for consumption as bequests to children (accidental bequests) ${ }^{1}$.

Savings thus motivated determine wealth accumulation over the life time, wealth distribution across heterogeneous people and aggregate capital accumulation. How important are the above mentioned savings motives for people with different ages and incomes, and how do they influence the wealth distribution and the aggregate wealth?

The question is interesting and important by itself, but it is even more important because of the policy implications associated with it. Effects of policies that redistribute resources across people with different incomes, such as public transfer programs, estate taxation, unemployment insurance, public health insurance, or social security, are critically dependent on the relative importance of different savings motives. For example, if savings among young individuals are motivated by precautions rather than by life-cycle concerns, policies that deliver income insurance would decrease their savings. As a result, wealth inequality between young and old generations might increase and total capital accumulation might decrease. Alternatively, if the life-cycle motive is strong among them, they would still keep savings for the future, so wealth inequality and capital accumulation would be insensitive to these policies.

Many empirical studies based on available data tackled the question. These analyses tried to disentangle wealth for the purpose of intergenerational transfers from wealth generated by the life-cycle motive. They can be divided into two groups, those that follow an accounting approach and those that use a direct questionnaire approach. The accounting-based approach estimates the wealth accumulated

\footnotetext{
${ }^{1}$ Intergenerational transfers might be caused by different motivations. For example, Kotlikoff and Spivak (1981) assumes that parents transfer resources to children in return for old age support. This type of transfer motive is not considered in the paper.
} 
for intergenerational transfers as the accumulated net surplus of earnings over consumption. In this branch of literature there are papers by Kotlikoff and Summers (1981), Ando and Kennickell (1987), Kotlikoff (1988), and Modigliani (1988). The direct approach uses surveys asking people what share of their wealth is held for the purpose of intergenerational transfers. Exponents of this group are papers by Modigliani (1988) and Hurd and Mundaca (1989).

Although these estimates give valuable information, there are caveats associated with them. First, the estimates are sensitive to a variety of assumptions concerning the age of family formation, the age of retirement, and the age of death; the shape and stability over time of age-earnings and ageconsumption profiles, and of relative wages; and the definition of durable goods as consumption or investment (Blinder, 1988). Second, the estimates do not separate different savings motives in a fundamental sense. The calculation of life-cycle savings does not distinguish the precautionary motive from the pure life-cycle motive. The estimates of transferred wealth do not tell how much transfers increase by the presence of uncertain lifetime and the absence of some insurance markets ${ }^{2}$.

Most importantly, different savings motives interact, so it is very difficult to isolate each motive as the above empirical studies attempted (Kessler and Masson, 1989). For example, consider an individual who received a certain amount of bequests from his parent. He can use this bequest to increase savings in order to finance his future consumption and/or to leave bequests for his child. This kind of savings is considered to be totally altruistically motivated by some researchers, but regarded as life-cycle savings by others, resulting in large discrepancies in the estimates even with the same data. The truth would be between the two extremes, but it cannot be known from the data. Taking another example, suppose that we want to know what fraction of bequests is altruistically motivated and what fraction is accidental. We would compare inherited bequests with the amount of wealth that respondents of a questionnaire intended to leave to their families for altruistic reasons. The problem with this decomposition is that the deceased may get some utility from bequests that are not intended for altruistic reasons initially.

Finally, these estimates may supply some information about the relative importance of different

\footnotetext{
${ }^{2}$ One empirical work free from this feature is the one by Gale and Scholz (1994). Noticing the difficulty of separating accidental transfers from total transfers, they directly estimated transfers excluding bequests, and found that such transfers account for at least 20 percent of aggregate wealth (bequests account for additional 30 percent of aggregate wealth). Their estimate suggests that the altruistically motivated savings is important even without uncertainty.
} 
savings motives for the current economy but not for the economy after some policies are changed. For instance, suppose that it is somehow found that individuals leave $60 \%$ of bequests for an altruistic reason and the rest is due to uninsured uncertain life-time (accidental bequests) in the current economy. Now suppose that the government increases estate taxation. Then people would try to reduce their bequests and increase their own consumption, because they obtain less utility from leaving a given amount of bequests. But wealth reserved for their own consumption may end up as accidental bequests since they do not know when they will die. As a result, a proportion of bequests left accidentally would increase.

Noticing the difficulties associated with the existing empirical studies, in order to tackle this question, we employ numerical simulations based on a realistic overlapping generations model with heterogeneity within generations. There are some papers employing numerical simulations such as Masson (1986), Laitner (1990), and Lord and Rangazas (1991). Our model is much more realistic in its structure and takes into account all the savings motives mentioned above. For this purpose, we compare the allocation of our baseline economy with those of three different economies: one with a complete annuity market, one without labor earnings uncertainty and one without altruism. By following this approach we indirectly measure the effects of precautionary savings, altruistic and accidental bequests motives on individual savings behavior and aggregate wealth accumulation. As noted above, we followed this approach because it is infeasible to isolate the effect of each of these motives simultaneously in any model or data set due to the fact that all these motives are working in conjunction.

In the model, an individual is born to a parent with particular levels of assets and earnings. When a child, the individual does not have any choices and just inherits and acquires ability. Once he becomes an adult, he starts working and then has a child. He receives earnings and capital income from his assets and allocates his income to current consumption and savings. The individual's earnings depend on his innate and acquired ability before he starts working, his age, and a stochastic component. Accumulated wealth comes from cumulative savings and inherited bequests. After a particular age, he retires and starts to face a probability of death, and once he dies he leaves his assets to his child as 
bequests. He derives utility from leaving bequests ${ }^{3}$. Inter vivos transfers are not modeled for technical difficulties. In the baseline economy, insurance markets are non-existent and loan markets are not available (credit constraint). Hence savings are the only way to self-insure against the risks associated with uncertain lifetime and earning shocks.

The parameters of the baseline economy are chosen so that the model matches the evolution of earnings across time and generations, and the distribution of earnings and wealth reasonably closely to those observed for the U.S. economy. The model succeeds not only in matching the overall distribution of earnings and wealth but also in reproducing distributions for subgroups of the population.

In addition to the literature on relative importance of different savings motives cited above, this paper is also related to the research on consumption and savings behaviors that use numerical methods to examine the issue, which includes Deaton (1991, 1992), Hubbard, Skinner, and Zeldes $(1994,1995)$, Gourinchas and Parker (2002), De Nardi (1999), Cagetti (2000), and Gokhale et.al (2001). This work is also somewhat related to the research that searches for models that can quantitatively reproduce the observed wealth distribution to a high degree, such as Quadrini and Rios-Rull (1997), Laitner (2000), and Castaneda, Diaz-Gimenez, and Rios-Rull (2000).

The paper is organized as follows. The baseline model, which is supposed to reflect the actual U.S. economy, is described in Section 2 and the competitive equilibrium for this economy is defined in Section 3. Section 4 presents the hypothetical economies where complete insurance markets for uncertainties are available. Section 5 describes detailed procedures to calibrate the baseline model to the U.S. economy and Section 6 presents and explains results of numerical simulations. Section 7 concludes the paper.

\section{Economic Environment}

In this section, the baseline model that is calibrated to the U.S. economy in numerical examinations is presented. The underlying economic environment is a discrete-time overlapping generations world. In

\footnotetext{
${ }^{3}$ That is, altruism is 'impure' as in the models by Yaari (1966) and Blinder (1973). Pure altruism, where the individual cares about the utility of his child (as in Barro, 1974 and Becker, 1974), is not assumed in the paper. Pure altruism brings strategic interactions across generations in a realistic overlapping generations model as the one in the paper, and could lead to multiple competitive equilibria.
} 
this economy, an individual's life is divided into three parts, childhood, adulthood before retirement, and adulthood after retirement.

During his childhood he makes no economic decisions, so his age in the model is labeled only for his adulthood. In the model, 1 period is assumed to correspond to 5 years, and it is assumed that an individual lives up to 12 periods. This period setting is made for easing computational burdens.

An adult before retirement, who is between age 0 (age 25-29 in real life) and age 6 (age 5559 in real life), is called a young adult. A young adult receives income from work, assets holdings, bequests from his parent, if any, and a lump-sum transfer from the government, and makes decisions on consumption and assets holdings for the next period. He has a child at age 1 (age 30-34). His parent, who is 6 periods older than him, leaves him assets at death as bequests, because of a joy of giving and uncertain time of death. He supplies a fixed amount of time (normalized to 1) for work each period. Earnings depend on his innate and acquired ability before becoming an adult, his age (work experience), and a stochastic shock, which reflects all the stochastic changes in earnings during the working period. During this period, the agent faces two types of risks, labor earnings uncertainty and uncertainty about his parent's living status.

When turning age 7 (age 60-64 in real life), he retires and faces a probability of death for each year (including age 7) of his remaining life. An adult after retirement is called an old adult. He receives income from social security benefits and asset holdings, and makes decisions on consumption and asset holding for the next period. His social security receipt depends on the average earnings during his working period, which is a good approximation of the current U.S. social security system. After age 11 (age 80-84 in real life) he dies for certain. Figure 1 presents the generational structure of the model. The following subsections describe the model in detail.

\subsection{Generational Structure}

As explained above, an individual's adult life starts at age 0 and may last up to age 11. Since age 7 , that is after retirement, he faces a probability of death. His parent is 6 periods older than him, and his child is 6 periods younger than him. In this setting only two generations coexist as living adults 


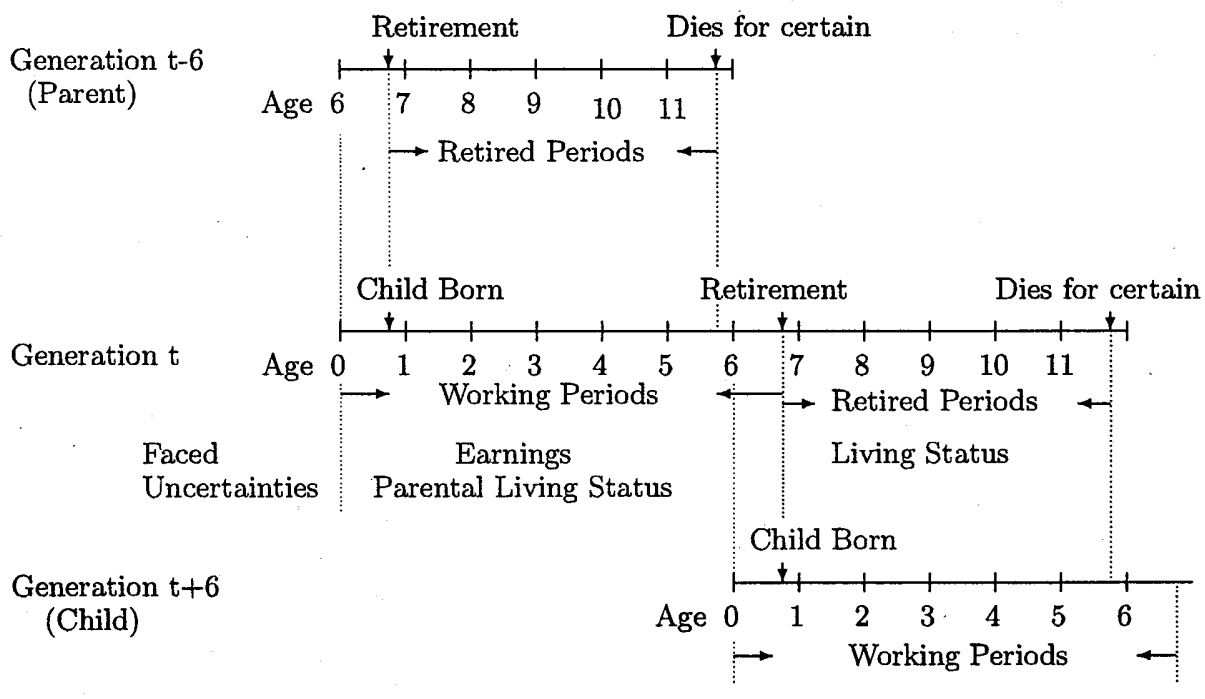

Figure 1: Generational Structure

within a lineage, which simplifies the analysis ${ }^{4}$. The number of deaths and births in the economy is assumed to be the same each period so that the population of the economy is constant over time. The probability of surviving between age $j$ and age $j+1$ conditional on surviving up to age $j$ is denoted by $p_{j}$, with $p_{j}=1$, for $j=0,1, \cdots, 5 ; p_{j} \in(0,1)$ for $j=6,7, \cdots, 10$, and $p_{11}=0$.

\subsection{Consumer's maximization problem}

An individual derives utility from the flow of his consumption when alive and from bequests transferred to his child upon his death. Note that he cares about the bequests left to his child, but not about consumption of his child. That is, he has 'impure altruism'. As mentioned in the introduction, if the individual is assumed to care about the consumption of his child, and both maximize utility as different economic units, strategic interactions across generations would arise in the model. This would increase the complexity of the analysis and therefore this simpler assumption is made. Let $c_{j}$ and $a_{j}$ be his consumption and assets at age $j$. Denote his momentary utility function from consumption by $U(\cdot)$ and from bequests by $F(\cdot)$, respectively. Let the discount factor on future utilities be $\beta$. Then his expected lifetime utility is given by the following expression:

\footnotetext{
${ }^{4}$ If the generational structure allows for the coexistence of three generations as adults, then different types of bequests (from a grandparent to a grandchild, or from a parent to a child and a grandparent) could arise and complicates the analysis greatly without changing the model's implications much.
} 


$$
E_{0}\left[\sum_{j=0}^{6} \beta^{j} U\left(c_{j}\right)+\sum_{j=7}^{11} \beta^{j}\left(\Pi_{k=0}^{j-2} p_{k}\right)\left\{p_{j-1} U\left(c_{j}\right)+\left(1-p_{j-1}\right) F\left(a_{j}\right)\right\}+\beta^{11}\left(\Pi_{k=0}^{10} p_{k}\right) F\left(a_{12}\right)\right]
$$

The expectation operator $E_{0}$ is attached to the above expression to indicate that as of period zero there are other types of risks (mentioned below) aside from the risk associated with the date of death. An individual survives until age $j-1$ with probability $\Pi_{k=0}^{j-2} p_{k}{ }^{5}$. With probability $p_{j-1}$, he survives the next period and obtains the utility from consumption of goods, $c_{j}$. With probability $1-p_{j-1}$, he dies before becoming age $j$ and obtains utility from leaving bequests, $a_{j}$. After age 11 , he dies with certainty and obtains utility from bequests, $a_{12}$. Future utility is discounted accordingly.

Assume that the functions $U(\cdot)$ and $F(\cdot)$ are strictly increasing and strictly concave. Further assume that $\lim _{c \rightarrow 0} U^{\prime}(c)=\infty$ and $\lim _{b \rightarrow 0} F^{\prime}(b)<\kappa<\infty$, where $\kappa$ is a positive real number. The latter assumption is imposed in order to allow zero bequests for a portion of the population.

The individual chooses consumption and assets plans in order to maximize his expected utility subject to the following constraints:

$$
\left(1+\tau_{c}\right) c_{j}+a_{j+1}=\left(1-\tau_{l}\right) w l_{j}+\left[1+\left(1-\tau_{k}\right) r\right] a_{j}+t r, \text { for } j \in\{0,1, \cdots, 6\}
$$

if the parent did not die in this period,

$$
\left(1+\tau_{c}\right) c_{j}+a_{j+1}=\left(1-\tau_{l}\right) w l_{j}+\left[1+\left(1-\tau_{k}\right) r\right]\left(a_{j}+b_{j}\right)+t r, \text { for } j \in\{1, \cdots, 6\}
$$

if the parent died in this period,

$$
\begin{aligned}
\left(1+\tau_{c}\right) c_{j}+a_{j+1} & =\operatorname{soc}_{j}+\left[1+\left(1-\tau_{k}\right) r\right] a_{j}, \text { for } j \in\{7,8, \cdots, 11\} \\
\text { and } a_{j+1} & \geq 0, \text { for } j \in\{0,1, \cdots, 11\}
\end{aligned}
$$

where $a_{j+1}$ represents the asset holdings at age $j+1$ and $b_{j}$ is bequests received at age $j$ from his parent, if any. Further, $r, w$, and $l_{j}$ are the interest rate, the wage rate per efficiency unit of labor, and his effective labor supply at age $j$, respectively. Finally, $\tau_{c}, \tau_{l}$, and $\tau_{k}$ are tax rates on consumption,

\footnotetext{
${ }^{5}$ Since $p_{j}=1$ for $j=0,1, \cdots, 5$ is satisfied, $\Pi_{k=0}^{j-1} p_{k}$ is not attached to the first term of the above expression.
} 
labor income and capital income, respectively, $t r$ is a lump-sum transfer received during his working periods, and $s o c_{j}$ denotes his social security receipt at age $j$. He faces a borrowing constraint each period so that he has to keep non-negative assets each period, which also implies that he cannot leave negative bequests to his child ${ }^{6}$.

Since an individual may receive bequests upon his parent's death, he needs to form expectations of his future bequests receipt to solve the maximization problem. Assume that he has full access to the parent's information required to predict his future bequests, that is, the information needed to solve the parent's maximization problem after retirement (death can occur only after retirement). In order to simplify numerical computations, it is further assumed that the young individual solves his decision problem after observing his parent's current decisions.

\subsection{Earnings Process}

The agent's effective labor supply $l_{j}$ depends on his inherited and acquired ability before becoming an adult (earnings ability), his age (work experience), and a stochastic shock (earnings shock). Assume the following functional form for the effective labor supply,

$$
l_{j}=\theta \phi_{j} \eta_{j}
$$

where $\theta$ is the earnings ability, $\phi_{j}$ is an age-dependent deterministic component, and $\eta_{j}$ is the earnings shock.

The earnings ability, $\theta$, captures all the ability inherited or acquired before becoming an adult, which would depend on his innate ability, nurture, education, and family and environments he grew up in, although none of these dependencies are explicitly modeled. $\theta$ is time-invariant throughout an individual's life, but it is correlated with his parent's earnings ability and follows the following stochastic process.

$$
\log \theta=\rho \log \theta_{p}+\epsilon, \epsilon \sim N\left(0, \sigma_{\varepsilon}^{2}\right), \text { i.i.d, }
$$

\footnotetext{
${ }^{6}$ There is a large literature on endogenous borrowing constraints, but due to the computational complication, the simpler exogenous constraint is assumed.
} 
where $\theta_{p}$ is the earnings ability of his parent and $\epsilon$ is a stochastic shock to the process, which follows an i.i.d. normal distribution ${ }^{7}$.

The time-varying earnings shock, $\eta_{j}$, captures all the shocks to earnings after an individual starts working, which would include changes in his employment status, his job performance, health condition, the performance of the company he works for, etc. The shock is assumed to follow the following AR(1) process in logs,

$$
\log \eta_{j}=\zeta \log \eta_{j-1}+v_{j}, v_{j} \sim N\left(0, \sigma_{\nu}^{2}\right), \text { i.i.d }
$$

where $\eta_{j-1}$ is the earnings ability in the previous period (at age $j-1$ ) and $v_{j}$ is a stochastic shock to the process, which follows an i.i.d. normal distribution.

\subsection{Recursive Formulation}

The above maximization problem is reformulated in a recursive way so that decision problems and state variables at every stage of life are stated clearly. This recursive formulation is used for solving the model numerically.

\subsubsection{Young adult's problem I (While his parent is alive)}

A young adult, who is between age 0 and age 5 and has a living parent, earns income through his job and assets, and may receive bequests next period if his parent dies. The agent has no uncertainty regarding his own life span. So, his dynamic programming problem at age $j(0 \leq j \leq 5)$ reads as follows,

$$
\begin{aligned}
& V^{j}\left(\theta, \eta, \bar{l}, a, s^{p} ; S\right)=\max _{c, a^{\prime}}\{U(c)+ \\
& \left.\beta E\left[p_{j+6} V^{j+1}\left(\theta, \eta^{\prime}, \bar{l}^{\prime}, a^{\prime}, s^{p \prime} ; S^{\prime}\right)+\left(1-p_{j+6}\right) \widetilde{V}^{j+1}\left(\theta, \eta^{\prime}, \bar{l}^{\prime}, a^{\prime}, s^{p \prime} ; S^{\prime}\right)\right]\right\}
\end{aligned}
$$

\footnotetext{
${ }^{7}$ Since decisions on human capital investment are not explicitly modeled, the above process captures all the sources of the intergenerational correlation of earnings including genetic transmission of ability and effects of incomplete markets on human capital investment.
} 


$$
\text { subject to } \begin{aligned}
\left(1+\tau_{c}\right) c+a^{\prime} & =\left(1-\tau_{l}\right) w l+\left[1+\left(1-\tau_{k}\right) r\right] a+t r \\
l & =\theta \phi(j) \eta \\
\bar{l}^{\prime} & =\left\{\theta \phi(j+1) \eta^{\prime}+j \cdot \bar{l}\right\} /(j+1), \\
\log \eta^{\prime} & =\zeta \log \eta+v^{\prime}, v^{\prime} \sim N\left(0, \sigma_{\nu}^{2}\right), i . i . d, \\
a^{\prime} & \geq 0 \\
s^{p \prime} & =\Upsilon\left(s^{p}\right), \\
\text { and } S^{\prime} & =\Psi(S) .
\end{aligned}
$$

In equation (9), $V^{j}\left(\theta, \eta, \bar{l}, a, s^{p} ; S\right)$ is his expected discounted welfare at age $j$;

$V^{j+1}\left(\theta, \eta^{\prime}, \bar{l}^{\prime}, a^{\prime}, s^{p \prime} ; S^{\prime}\right)$ and $\tilde{V}^{j+1}\left(\theta, \eta^{\prime}, \bar{l}^{\prime}, a^{\prime}, s^{p \prime} ; S^{\prime}\right)$ are the next period's welfare when his parent is still alive and when his parent dies, respectively; $\beta$ is a discount factor on future utilities; $p_{j+6}$ is the current conditional probability of his parent (of age $j+6$ ) surviving the next period; and $E$ is the expectation operator conditional on the information available in the current period. In the budget constraint (10), $c$ is consumption, $l$ is effective labor supply, $a$ is assets (variables with superscript '"' denote variables for the next period). The wage rate per effective labor supply is denoted by $w$ and the interest rate is denoted by $r$. Tax rates on consumption, labor income and capital income are expressed by $\tau_{c}, \tau_{l}$ and $\tau_{k}$, respectively. $t r$ is a lump-sum transfer from the government. The effective labor supply $l$ is dependent on the time-invariant earnings ability, $\theta$, the age-dependent deterministic component $\phi(j)$, and the stochastic component $\eta$, which follows an $\operatorname{AR}(1)$ process in logs (equation 11 and 13). The average effective labor supply up to this period $\bar{l}$ is a component of his state vector because the future social security benefit is dependent on it. A vector of state variables for his parent $\left(s^{p}\right)$ is needed to predict his bequests receipt (the exact component of the vector is explained below) and the transition function for this vector is denoted $\Upsilon(\cdot)$ (equation 15). The aggregate state of the world is represented by a vector $S$ and $\boldsymbol{\Psi}(\cdot)$ characterizes the evolution of the aggregate state (equation 16). 


\subsubsection{Young adult's problem II (After his parent dies)}

In the period his parent dies, the young adult at age $j(1 \leq j \leq 5)$ receives bequests and solves the following problem:

$$
\widetilde{V}^{j}\left(\theta, \eta, \bar{l}, a, s^{p} ; S\right)=\max _{c, a^{\prime}}\left\{U(c)+\beta E\left[W^{j+1}\left(\theta, \eta^{\prime}, \bar{l}^{\prime}, a^{\prime} ; S^{\prime}\right)\right]\right\}
$$

subject to

$$
\left(1+\tau_{c}\right) c+a^{\prime}=\left(1-\tau_{l}\right) w l+\left[1+\left(1-\tau_{k}\right) r\right](a+b)+t r
$$

and equations (11), (12), (13), (14) and (16).

In the above formulation, $W^{j+1}\left(\theta, \eta^{\prime}, \bar{l}^{\prime}, a^{\prime} ; S^{\prime}\right)$ is his welfare in the next period and $b$ is the bequest received from his parent, which is dependent on his parent's state $s^{p}$. Since the young adult is assumed to have enough information to know his parent's states after retirement, $b$ coincides with the parent's optimal asset plan at age $j+6$ (determined at age $j+5$ ) when the parental state is $s^{p}$. Note that the function $W^{j+1}$ does not depend on $s^{p}$ since he has already received bequests.

From the next period on, the young adult solves the following problem:

$$
W^{j}(\theta, \eta, \bar{l}, a ; S)=\max _{c, a^{\prime}}\left\{U(c)+\beta E\left[W^{j+1}\left(\theta, \eta^{\prime}, \bar{l}^{\prime}, a^{\prime} ; S^{\prime}\right)\right]\right\}
$$

subject to equations (10), (11), (12), (13), (14) and (16).

\subsubsection{Maximization Problem at age 6}

In the next period (at age 7), he becomes a retiree, starts receiving a social security payment and faces a positive probability of death. By this age his parent is dead with certainty (See Figure 1), and now he has to care about the event of his child inheriting his assets.

If his parent is dead before the previous period, he solves the following problem:

$$
W^{6}(\theta, \eta, \bar{l}, a ; S)=\max _{c, a^{\prime}}\left\{U(c)+\beta\left[p_{6} J^{7}\left(\bar{l}, a^{\prime} ; S^{\prime}\right)+\left(1-p_{6}\right) F\left(a^{\prime}\right)\right]\right\}
$$


subject to equations $(10),(11),(14)$ and (16), where $p_{6}$ is the agent's current conditional probability of surviving the next period, $J^{7}\left(\bar{l}, a^{\prime} ; S^{\prime}\right)$ is the welfare at age 7 if he is still alive, and $F\left(a^{\prime}\right)$ is the utility associated with leaving bequests if he dies. Note that function $J^{7}$ does not depend on $\theta$ and $\eta$ anymore because he retires after this period.

If his parent was alive in the previous period, he solves the problem below.

$$
\widetilde{V}^{6}\left(\theta, \eta, \bar{l}, a, s^{p} ; S\right)=\max _{c, a^{\prime}}\left\{U(c)+\beta\left[p_{6} J^{7}\left(\bar{l}, a^{\prime} ; S^{\prime}\right)+\left(1-p_{6}\right) F\left(a^{\prime}\right)\right]\right\}
$$

subject to equations (18), (11), (14), and (16).

\subsubsection{Old Adult's Problem}

After retirement, the individual receives social security benefits, and faces a positive probability of death. An old adult at age $j(7 \leq j \leq 11)$ solves the following problem.

$$
J^{j}(\bar{l}, a ; S)=\max _{c, a^{\prime}}\left\{U(c)+\beta\left[p_{j} J^{j+1}\left(\bar{l}, a^{\prime} ; S^{\prime}\right)+\left(1-p_{j}\right) F\left(a^{\prime}\right)\right]\right\}
$$

subject to

$$
\left(1+\tau_{c}\right) c+a^{\prime}=\operatorname{soc}(\bar{l})+\left[1+\left(1-\tau_{k}\right) r\right] a,
$$

(14) and (16).

In the above formulation, $J^{j+1}\left(\bar{l}, a^{\prime} ; S^{\prime}\right)$ is the welfare in the next period if he is still alive, $F\left(a^{\prime}\right)$ is the utility from leaving bequests if he dies, and $\operatorname{soc}(\bar{l})$ denotes his social security receipt, which depends on his average earnings during his working life $\bar{l}$. Note that the individual dies before becoming age 12 with probability 1 , so that $p_{11}=0$.

From the formulation of the maximization problem, it is now clear that the vector of parental state variables needed for a child to predict bequests is $s^{p}=\left(j^{p}, \bar{l}^{p}, a^{p \prime}\right)$, where $j^{p}$ is age, $\bar{l}^{p}$ is lifetime average effective labor supply, and $a^{p \prime}$ is the next period's assets of his parent, respectively. The variable $a^{p \prime}$ is the current state variable because a child makes decisions after observing his parent's decisions by assumption. 


\subsection{Final Goods Production}

The firm hires capital and labor and solves the profit maximization problem,

$$
\max \{O(\mathbf{k}, \mathbf{l})-w \mathbf{l}-(r+\delta) \mathbf{k}\}
$$

where $O(\cdot)$ denotes the CRS final goods production function, $\mathbf{k}$ and $\mathbf{l}$ denote aggregate capital and efficiency labor, respectively, and $\delta$ is the depreciation rate of physical capital. The first-order conditions associated with the firm's problem provide the real interest rate and wage rate as functions of the capital-efficiency labor ratio.

\subsection{Governmental Policies}

The government taxes labor income, capital income and consumption to finance the lump-sum transfer, social security and other policies. The policies other than the transfer policies are consumption of final goods by the government and are assumed not to affect an individual's utility. The government's budget constraint reads,

$$
\operatorname{tr}+\mathbf{s o c}+\mathbf{c}_{g}=\tau_{l} w \mathbf{l}+\tau_{k} r \mathbf{k}+\tau_{\mathbf{c}} \mathbf{c}
$$

where $\operatorname{tr}$ is the total lump-sum transfer, soc is the total social security payment, and $\mathbf{c}_{g}$ is the spending on other policies.

\section{Recursive Competitive Equilibrium}

The analyses in later sections focus on a stationary recursive competitive equilibrium where decision problems are recursive, and the aggregate state of the world and governmental policies are timeinvariant. The followings are the formal definitions of a recursive competitive equilibrium and of a stationary recursive competitive equilibrium.

Definition 1 A Recursive Competitive Equilibrium for the economy consists of:

(i) the value functions 
$\left\{V^{j}\left(\theta, \eta, \bar{l}, a, s^{p} ; S\right)\right\}_{j=0}^{5},\left\{\widetilde{V}^{j}\left(\theta, \eta, \bar{l}, a, s^{p} ; S\right)\right\}_{j=1}^{6},\left\{W^{j}(\theta, \eta, \bar{l}, a ; S)\right\}_{j=2}^{6}$, and $\left\{J^{j}(\bar{l}, a ; S)\right\}_{j=7}^{11} ;$

(ii) the decision rules

a) for a young adult with a living parent, $\left\{A_{V}^{j}\left(\theta, \eta, \bar{l}, a, s^{p} ; S\right), C_{V}^{j}\left(\theta, \eta, \bar{l}, a, s^{p} ; S\right)\right\}_{j=0}^{5}$;

b) for a young adult who has just lost his parent, $\left\{A_{\widetilde{V}}^{j}\left(\theta, \eta, \bar{l}, a, s^{p} ; S\right), C_{\widetilde{V}}^{j}\left(\theta, \eta, \bar{l}, a, s^{p} ; S\right)\right\}_{j=1}^{6}$;

c) for a young adult whose parent is dead, $\left\{A_{W}^{j}(\theta, \eta, \bar{l}, a ; S), C_{W}^{j}(\theta, \eta, \bar{l}, a ; S)\right\}_{j=2}^{6}$;

d) for an old adult, $\left\{A_{J}^{j}(\bar{l}, a ; S), C_{J}^{j}(\bar{l}, a ; S)\right\}_{j=7}^{11}$;

(iii) the price functions $W$ and $R$;

(iv) the governmental policies $\tau_{l}, \tau_{k}, \tau_{c}, \operatorname{tr}, \operatorname{soc}(\bar{l})$ and $\mathbf{c}_{\mathbf{g}}$;

(v) the law of motion for the parent's state of the world $s^{p}=\left(j^{p}, \overline{l^{p}}, a^{p \prime}\right), \Upsilon$;

and

(vi) the law of motion for the aggregate state of the world $S \equiv S_{V} \times S_{\tilde{V}} \times S_{W} \times S_{J}, \Psi$, where $S_{V}$ is the joint distribution of $j, \theta, \eta, \bar{l}, a$, and $s_{p}$ for young adults with alive parents, $S_{\widetilde{V}}$ is the joint distribution of the same variables for young adults who have just lost their parents, $S_{W}$ is the joint distribution of $j, \theta, \eta, \bar{l}$, and a for young adults whose parents are dead, and $S_{J}$ is the joint distribution of $j, \bar{l}$, and a for old adults ;

such that,

1. An age $j(0 \leq j \leq 5)$ young adult with a living parent solves problem (9), with the maximized value function given by $V^{j}$ and the decision rules by $A_{V}^{j}$ and $C_{V}^{j}$.

2. An age $j(1 \leq j \leq 6)$ young adult who have just lost his parent solves problem (17), with the maximized value function given by $\tilde{V}^{j}$ and the decision rules by $A_{\widetilde{V}}^{j}$ and $C_{\tilde{V}}^{j}$ (When he is age 6 , he solves problem 21).

3. An age $j(2 \leq j \leq 6)$ young adult whose parent is dead solves problem (19), with the maximized value function given by $W^{j}$ and the decision rules by $A_{W}^{j}$ and $C_{W}^{j}$ (When he is age 6, he solves problem 20).

4. An age $j(7 \leq j \leq 11)$ old adult solves problem (22), with the maximized value function given by $J^{j}$ and the decision rules by $A_{J}^{j}$ and $C_{J}^{j}$.

5. The law of motion for the parent's state of the world $s^{p}=\left(j^{p}, \overline{l^{p}}, a^{p \prime}\right), \Upsilon$ is composed of the following set 
of equations:

$$
\begin{gathered}
j^{p \prime}=j^{p}+1, \\
a^{p \prime}=A_{J}^{j+6}\left(a^{p}, \overline{l^{p}} ; S\right), \\
\text { and } \quad{\overline{l^{p}}}^{\prime}=\overline{l^{p}} .
\end{gathered}
$$

A young adult's prediction of the future bequests is consistent with the actual bequests received from his parent when state $s^{p}$ is realized.

6. The firm solves problem (24), with the first-order conditions given by $R=O_{1}(\mathbf{k}, 1)-\delta$ and $W=O_{2}(\mathbf{k}, 1)$, where $\mathbf{k}$ and $\mathbf{l}$ are given by

$$
\begin{gathered}
\mathbf{k}=\sum_{j=0}^{11}\left[\int a \cdot d S\right] \\
\text { and } \mathbf{l}=\sum_{j=0}^{6}\left[\int \theta \phi(j) \eta \cdot d\left(S_{V} \times S_{\tilde{V}} \times S_{W}\right)\right] .
\end{gathered}
$$

7. The government's budget constraint is satisfied, i.e.

$$
\begin{aligned}
\mathbf{t r}+\mathbf{s o c}+\mathbf{c}_{\mathbf{g}}= & \boldsymbol{\tau}_{\mathbf{c}} \mathbf{c}+\boldsymbol{\tau}_{\mathbf{l}} \mathbf{w l}+\boldsymbol{\tau}_{\mathbf{k}} \mathbf{r k} \\
\text { where soc }= & \sum_{j=7}^{11}\left[\int q(\bar{l}) \cdot d S_{J}\right] \\
\text { and } \mathbf{c}= & \sum_{j=0}^{6}\left[\int C_{V}^{j}(\cdot) \cdot d S_{V}+\int C_{\tilde{V}}^{j}(\cdot) \cdot d S_{\tilde{V}}+\int C_{W}^{j}(\cdot) \cdot d S_{W}\right] \\
& +\sum_{j=7}^{11}\left[\int C_{J}^{j}(\cdot) \cdot d S_{J}\right] .
\end{aligned}
$$

and

8. The law of motion of the aggregate state of the world, $S$, is consistent with individual decisions, the firm's choices and governmental policies, and evolves according to

$$
S^{\prime}=\Psi(S)
$$


Definition 2 A stationary recursive competitive equilibrium is a recursive competitive equilibrium in which $S=\Psi(S)$ and the governmental policies are time-invariant.

\section{Completing Markets}

In the baseline economy described above, an individual self-insures against earnings uncertainty and lifetime uncertainty by accumulating wealth for a precautionary reason. When there are markets to insure against these risks, precautionary savings and accidental bequests disappear. In order to measure changes in the distribution of wealth and aggregate capital accumulation in the presence of such insurance markets, two hypothetical economies, the one with complete annuity markets, and the one without earnings uncertainty, are constructed in this section.

\subsection{Economy with Complete Annuity Markets}

Suppose that there is a complete annuity market so that an individual can insure against his uncertain

time of death. Let $\frac{1+r}{p_{j-1}}$ units of consumption of the next period be the gross return of one unit of the annuity security if the individual survives and nothing otherwise ${ }^{8}$. Let $\chi$ denote the fraction of assets that is annuitized. Therefore, at any point in time, if he were to die, the non-annuitized portion of his assets, $(1-\chi) a^{\prime}$, will be bequeathed to his child, while the annuitized portion, $\chi a^{\prime}$, will go to finance insurance claims of survivors.

Then the budget constraints of an individual over age 6 become

$$
\left(1+\tau_{c}\right) c+\left(1-\chi^{\prime}\right) a^{\prime}+\chi^{\prime} a^{\prime}=\left(1-\tau_{l}\right) w l+\left[1+\left(1-\tau_{k}\right) r\right] a+t r, \text { for } j=6
$$

$$
\begin{aligned}
\left(1+\tau_{c}\right) c+\left(1-\chi^{\prime}\right) a^{\prime}+\chi^{\prime} a^{\prime}=\operatorname{soc}(\bar{l})+\left[1+\left(1-\tau_{k}\right) r\right](1-\chi) a+ & \\
& {\left[1+\frac{\left(1-\tau_{k}\right)\left(1+r-p_{j-1}\right)}{p_{j-1}}\right] \chi a, \text { for } j=7, \ldots, 10 }
\end{aligned}
$$

\footnotetext{
${ }^{8}$ In this way the relative price of this security in terms of consumption is 1 . Clearly there are other equivalent ways to set up this market where the relative price is not one.
} 
and

$$
\begin{aligned}
& \left(1+\tau_{c}\right) c+a^{\prime}=\operatorname{soc}(\bar{l})+\left[1+\left(1-\tau_{k}\right) r\right](1-\chi) a+ \\
& \qquad \quad\left[1+\frac{\left(1-\tau_{k}\right)\left(1+r-p_{10}\right)}{p_{10}}\right] \chi a, \text { for } j=11 .
\end{aligned}
$$

Note that $\chi^{\prime}$ is an additional decision variable for those who are between age 6 and age 10 and $\chi$ is an additional state variable for those above age 7. The return of the annuity is higher than normal assets due to $p_{j-1}<1$. Hence, in the absence of altruism, the individual will hold all of his assets in an annuitized form, so that $\chi^{\prime}=1$.

\subsection{Economy with no earnings uncertainty}

In addition to annuity markets being incomplete, the baseline model has also assumed the absence of markets in which consumers can purchase insurance against earnings uncertainty. In order to set up complete insurance markets for the earnings uncertainty, one could introduce contingent claims just as above. However, due to computational difficulties we take a shortcut by considering the model economy where the earnings shock $\eta$ always takes a common value. The constant value of $\eta$ is set so that aggregate efficiency labor of this economy is at the same level as in the original economy ${ }^{9}$.

\section{Calibration}

In this section, the model's functional forms are specified and the parameter values are set for numerical simulations. The parameters are set based on existing empirical works, if available. Otherwise, they are set so that the simulated economy produces statistics that resemble those of the U.S. economy when policy parameters in the model are set based on actual policies.

\subsection{Final goods production and Preferences}

Final goods production function: The function is assumed to be of the standard Cobb-Douglas type:

\footnotetext{
${ }^{9}$ Recall that the complete markets economy will not be Pareto optimum due to distortionary taxation and the existence of the borrowing constraint. Therefore, solving the planner's problem will not deliver the market allocation.
} 


$$
\mathbf{O}(\mathbf{k}, \mathbf{l})=\mathbf{k}^{\alpha} \mathbf{l}^{1-\alpha}
$$

The parameter $\alpha$ is set to 0.36 , following most works in quantitative macroeconomics.

Depreciation rate for physical capital $\delta$ : The annual rate of depreciation is usually set between 0.08 and 0.10 in the quantitative business cycle literature. Choosing the midpoint of these estimates and noting that each period in the model corresponds to 5 years in real life, the depreciation rate for numerical simulations is set to be $1-(0.91)^{5}$.

Utility functions: The utility function for consumption of final goods is assumed to be of the CRRA variety:

$$
U(c)=\frac{c^{1-\sigma}-1}{1-\sigma}, \sigma>1
$$

The utility function for bequests is given by

$$
F\left(b^{\prime}\right)=b_{1}\left(1+\frac{b^{\prime}}{b_{2}}\right)^{1-\sigma}, \sigma>1
$$

The presence of 1 in the above expression permits some individuals to leave no bequests.

These preference parameters $\sigma, b_{1}$ and $b_{2}$, and the discount factor on future utilities $\beta$ are set so that the simulated model economy delivers a good overall match of the U.S. wealth distribution. The parameter values chosen for simulations are presented in the next section when simulation results of the baseline model are discussed.

\subsection{Earnings Process}

Remember that the effective labor supply $l$ of an individual of age $j$ is given by the following function,

$$
l=\theta \phi(j) \eta
$$

where $\theta$ is the earnings ability (time-invariant), $\phi(j)$ is the deterministic component at age $j$, and $\eta$ is the time-variant stochastic component (earnings shock). The earnings shock $\eta$ follows 


$$
\log \eta^{\prime}=\zeta \log \eta+v^{\prime}, \quad v^{\prime} \sim N\left(0, \sigma_{\nu}^{2}\right), \text { i.i.d. }
$$

The earnings ability $\theta$ is correlated across generations in the following manner,

$$
\log \theta=\rho \log \theta_{p}+\epsilon, \epsilon \sim N\left(0, \sigma_{\varepsilon}^{2}\right), \text { i.i.d., }
$$

where $\theta_{p}$ is the earnings ability of his parent.

The age-dependent deterministic component $\phi(j)$ is specified based on the empirical estimates by French (1999). He uses the PSID and the PSID validation study for the years 1978-1987 to estimate the stochastic process of labor earnings. His estimate of the deterministic component is:

$$
\phi(j)=0.18+j \times 0.099-j^{2} \times 0.0015+j^{3} \times 0.85 \times 10^{-5}-j^{4} \times 0.11 \times 10^{-7} .
$$

The AR processes for the innate ability and for the earnings ability are discretized based on the Tauchen (1986)'s procedure. The parameters $\rho, \sigma_{\nu}^{2}, \zeta$ and $\sigma_{\varepsilon}^{2}$ are difficult to set based on the existing empirical work and they are pinned down so that the simulated model produces earnings distribution and intergenerational correlations of earnings close enough to the corresponding statistics of the U.S. economy. The chosen parameter values are presented in the next section.

\subsection{Survival Probabilities}

The survival probabilities are taken from the 1985 Vital Statistics of the Life Tables for Health Statistics (1999) of the U.S. population. Since in the model an individual lives until turning age 7 (age 60-64 in real life) with certainty and dies with probability 1 after age 11 (age 80-84 in real life), the conditional survival probabilities are adjusted accordingly.

\subsection{Governmental Policies}

Recall that the government collects its revenue by levying taxes on labor income, capital income and consumption. The tax revenues are then used to finance lump-sum transfer, social security system 
and other policies. The non-transfer policies are consumption of final goods by the government and are assumed not to affect the individuals' utility. The government's budget constraint reads,

$$
\mathrm{tr}+\operatorname{soc}+\mathrm{c}_{g}=\tau_{\mathrm{c}} \mathrm{c}+\tau_{\mathrm{l}} \mathrm{wl}+\tau_{\mathrm{k}} \mathrm{rk}
$$

where $\mathbf{t r}$ is the total lump-sum transfer, soc is the total social security payment, $\mathbf{c}_{g}$ is the spending on other policies, and $\tau_{\mathbf{c}}, \tau_{\mathbf{l}}$, and $\boldsymbol{\tau}_{\mathbf{k}}$ are tax rates on consumption, labor income and capital income.

Social Security System: The social security payment is based on the average life-time labor earnings $\bar{l}$. Therefore, agents with different earnings histories receive different amounts of social security benefits. Assume that the social security benefit of an individual at age $j$ is determined by the following function,

$$
\operatorname{soc}_{j}(\bar{l})=\varsigma w \bar{l} .
$$

The parameter $\varsigma$ is set to be 0.4 . Then a retired worker gets $40 \%$ of the average of his lifetime labor earnings, which is close to the value $(42 \%)$ people with average earnings would receive in the U.S. economy, according to the information of the Social Security Administration. However, the actual social security system is progressive, so that people with higher earnings receive less than proportionally. In order to take into account this feature of the actual system, the computed average lifetime earnings $\bar{l}$ is adjusted accordingly ${ }^{10}$.

I'ax rates: The tax rates on labor income $\tau_{l}$, capital income $\tau_{k}$, and consumption $\tau_{c}$ are set to be equal to $0.2887,0.398$, and 0.0523 , respectively, following Mendoza, Razin, and Tesar (1994), who computed effective tax rates on factor incomes and consumption using national accounts and revenue statistics. The values are averages of their estimates for years 1980-1999.

Lump-sum transfer: The value of the lump-sum transfer to the working population tr is chosen so that the ratio of the transfer to GDP in the baseline economy becomes 0.031 , which is the average

\footnotetext{
${ }^{10}$ In particular, $\bar{l}$ is adjusted so that workers in particular positions of the earnings distribution receive the same proportions of their average lifetime earnings as they would when they retire before age 62 in the U.S. economy. The targeted workers are those who receive earnings at the national average level, $45 \%$ of the average earnings, and $160 \%$ of the average earnings steadily throughout their lives. These particular workers are chosen since their benefits examples are found in a document of the social security administration. The referred U.S. replacement ratios are the averages of the ratios for years $1990-99$.
} 
Table 1: Earnings Parameters [Baseline]

\begin{tabular}{|c|c|c|c|}
\hline$\zeta$ & $\sigma_{\nu}^{2}$ & $\rho$ & $\sigma_{\varepsilon}^{2}$ \\
\hline 0.4 & 0.392 & 0.7 & 0.303 \\
\hline
\end{tabular}

of the ratios in the U.S. economy for years 1980-1999. The U.S. transfers used to compute the ratios are sums of all the non-educational governmental transfers excluding social security, Medicare, and retirement benefits.

\section{Results}

\subsection{Baseline Model}

In this subsection, the calibration procedures for the remaining parameters of the earnings process and preferences are explained and the chosen parameter values are presented. Then the results of the simulated baseline economy are presented and compared with the data of the U.S. economy.

\subsubsection{Earnings Distribution}

The parameters of the earnings process are chosen so that the distribution of earnings and the evolution of earnings across time and generations are reasonably close to those observed for the U.S. economy. In particular, attention is paid to the following statistics: (i) the 'static' earnings distribution; Gini coefficient, proportion of the population without earnings, shares of earnings held by particular percentiles, ratio of earnings of the highest $1 \%$ to the lowest $40 \%$ of the distribution ${ }^{11}$, and mean to median ratio; (ii) its transition over time and over generations; 5 year correlation of log earnings for an individual ${ }^{12}$, and intergenerational correlation of log of life-time earnings; and (iii) the distributions for the skilled and unskilled labor; Gini for college and non-college graduates ${ }^{13}$, earnings ratio of college to non-college graduates. Table 1 presents the chosen parameter values.

Table 2 presents the statistics of the earnings distribution of the baseline economy and of the U.S.

\footnotetext{
${ }^{11}$ This is the ratio of average earnings that an individual in the highest $1 \%$ of the earnings distribution receives to average earnings that an individual in the lowest $40 \%$ receives.

${ }^{12}$ Remember that 1 period in the model corresponds to 5 years.

${ }^{13}$ Actually, Gini for people without college education is not available in the data. However, Gini for those with high school education and Gini for those without high school education are available, the numbers being 0.554 and 0.733 , respectively.
} 
economy. The statistics of the static U.S. earnings distribution are from Diaz-Gimenez, Quadrini and Rios-Rull (1997), who used the Survey of Consumer Finances (SCF) 1992 as the data source. The proportion of population without earnings is computed as the sum of the proportions with zero earnings and with negative earnings in the data, which are $24 \%$ and $0.42 \%$, respectively. The range of the values of the intergenerational correlation of lifetime earnings is based on Mulligan (1997), Solon (1992) and Zimmerman (1992). College graduates in the model are defined as those who are in the top $27 \%$ of the distribution of the earnings ability $\theta$. This value is the observed percentage of college graduates in the data used in Diaz-Gimenez, Quadrini and Rios-Rull (1997).

Table 2: Earnings Distribution [Baseline]

\begin{tabular}{||c|c|c||}
\hline \hline Statistics for Earnings Distribution & Baseline & U.S. economy \\
\hline \hline Gini coefficient & 0.6319 & 0.628 \\
\hline Proportion of population w/o earnings & $30.45 \%$ & $24.42 \%$ \\
\hline Share of earnings held by top 1\% & $10.26 \%$ & $14.76 \%$ \\
\hline Top 5\% & $29.19 \%$ & $31.13 \%$ \\
\hline Top 10\% & $43.34 \%$ & $43.51 \%$ \\
\hline Top 20\% & $63.2 \%$ & $61.39 \%$ \\
\hline Top 40\% & $85.38 \%$ & $84.72 \%$ \\
\hline Top 60\% & $97.19 \%$ & $97.21 \%$ \\
\hline Mean/Median & 146 & 211 \\
\hline Ratio of highest1\% to lowest 40\% & 1.768 & 1.65 \\
\hline 5 year correlation of log earnings & 0.7203 & $(\mathrm{n} / \mathrm{a})$ \\
\hline Intergenerational correlation of log-lifetime earnings & 0.4484 & $0.32-0.54$ \\
\hline Gini for college graduates & 0.5934 & 0.564 \\
\hline Gini for non-college graduates & 0.5763 & $(\mathrm{n} / \mathrm{a})$ \\
\hline Earnings ratio of college to non-college & 2.713 & 2.715 \\
\hline \hline
\end{tabular}

It should be stressed that with these few parameters the overall shape, the shape for each education group and transitions of the earnings distribution are matched satisfactorily. The match is not so successful for the extreme upper tail of the distribution and the proportion of the population with zero earnings. In the model the upper tail has lower concentration than in the data, and the proportion of the population with no earnings is higher than observed. In the model, everyone retires when turning age 7 (age 60-64 in real life), but many retire at older ages in the actual economy, which would be the reason for this higher proportion. ${ }^{14}$. Since the U.S. statistic for the 5 year correlation of log earnings is not available, in a later section, the sensitivity of results is checked by performing experiments with

\footnotetext{
${ }^{14}$ Another possible reason for the discrepancy would be that the basic economic unit in the data is a household that includes a person or a couple who live together and all other financially dependent individuals who live in the same household. As a result, there are cases where the head of the household is retired but other individuals in the same household are still in the labor force.
} 
different values for the correlation coefficient of the earnings shock process, $\zeta$.

\subsubsection{Wealth Distribution}

The preference parameters $\beta, \sigma, b_{1}$ and $b_{2}$ are of fundamental importance in determining the shape of the simulated wealth (assets) distribution. They are set so that the simulated economy matches the U.S. wealth distribution in: (i) its overall distribution; Gini, proportion of people without wealth, shares of wealth held by particular percentiles, mean to median ratio, and ratio of wealth of the highest $1 \%$ to the lowest $40 \%$ of the distribution; (ii) its distribution within the working population and the retired population; Gini and proportion of people without assets for each group; and (iii) the distributions among college and non-college graduates; Gini for each group. Table 3 shows the chosen parameter values ${ }^{15}$.

Table 3: Preference Parameters
\begin{tabular}{|c|c|c|c|}
\hline$\beta$ & $\sigma$ & $b_{1}$ & $b_{2}$ \\
\hline$(0.96)^{5}$ & 4.0 & -0.175 & 19.0 \\
\hline
\end{tabular}

Table 4: Wealth Distribution [Baseline]

\begin{tabular}{||c|c|c||}
\hline \hline Statistics for Wealth Distribution & Baseline & U.S. economy \\
\hline \hline Gini for the whole population & 0.7810 & 0.7810 \\
\hline Proportion of population without wealth & $20.71 \%$ & $6.9 \%$ \\
\hline Share of wealth held by top 1\% & $24.17 \%$ & $29.55 \%$ \\
\hline Top 5\% & $49.78 \%$ & $53.50 \%$ \\
\hline Top 10\% & $64.34 \%$ & $66.12 \%$ \\
\hline Top 20\% & $80.22 \%$ & $79.49 \%$ \\
\hline Top 40\% & $94.47 \%$ & $92.92 \%$ \\
\hline Top 60\% & $99.2 \%$ & $98.64 \%$ \\
\hline Mean/Median & 4.134 & 3.61 \\
\hline Highest 1\%/Lowest 40\% & 1207 & 875 \\
\hline Gini for working population & 0.7992 & $(\mathrm{n} / \mathrm{a})$ \\
\hline Proportion of working population w/o wealth & $24.83 \%$ & $(\mathrm{n} / \mathrm{a})$ \\
\hline Gini for retired population & 0.7383 & 0.7250 \\
\hline Proportion of retired population w/o wealth & $11.3 \%$ & $(\mathrm{n} / \mathrm{a})$ \\
\hline Gini for college graduates & 0.7356 & 0.7640 \\
\hline Gini for non-college graduates & 0.7411 & $0.734 / 0.752$ \\
\hline \hline
\end{tabular}

Table 4 presents the statistics of the wealth distribution. The statistics for the U.S. wealth distri-

\footnotetext{
${ }^{15}$ The presented Gini for retirees in the U.S economy is the Gini for individuals aged above 65. The Gini for those aged between 61 and 65 is 0.744 . The corresponding U.S. statistic for the Gini for non-college graduates is the Gini for high school graduates (0.734) and the Gini for those without high school education (0.752).
} 
Table 5: Bequests Distribution [Baseline]

\begin{tabular}{||c|c||}
\hline \hline Statistics for Bequests Distribution & Baseline \\
\hline \hline Gini & 0.8289 \\
\hline Proportion of population without bequests & $37.11 \%$ \\
\hline \hline
\end{tabular}

bution are from Diaz-Gimenez, Quadrini and Rios-Rull $(1997)^{16}$.

The simulated economy delivers a tight match to the U.S. wealth distribution. In particular, the Gini coefficient for the whole population, the shares of wealth held by top 10,20 , and $40 \%$ of the distribution, and the Gini for non-college graduates are almost identical to the corresponding values of the U.S. data. On the other hand, the proportion of the whole population without wealth is much less and the share of wealth held by top 1 is lower than the corresponding U.S. statistics. Although the proportion of the population without wealth of the calibrated model looks far from the reality, it is actually not, since about $24 \%$ of the population in the U.S. data hold wealth that is virtually indistinguishable from zero ${ }^{17}$. The higher proportion of non-wealth population might be caused by the higher population without earnings in the model, as noted above. Another factor causing this gap may be the fact that the model does not consider inter-vivos transfers, and as a result, the working population may hold less wealth than actually observed.

Figure 2 displays the age-wealth profiles for people who are in the top $20 \%$, middle $40 \%$, and bottom $40 \%$ of the earnings ability $(\theta)$ distribution ${ }^{18}$. They can be considered as the profiles of different education groups.

When individuals are very young, they hold only small amounts of assets. However, over time they steadily increase wealth holdings partly because more of them receive bequests from their parents. This can been seen clearly from Figure 3 , which plots age against average inherited bequests ${ }^{19}$. The bequests receipts increase with age until age 3 (age 40-44 in real life), then slightly decrease. Comparing the graphs for wealth and bequests, it is clear that, before age 3 , wealth is accumulated mainly through

\footnotetext{
${ }^{16}$ The presented U.S. statistic for the proportion of the population without wealth is the sum of the proportions of individuals with zero wealth $(3.4 \%)$ and of those with negative wealth $(3.5 \%)$.

${ }^{17}$ To be more accurate, in the histogram of the wealth distribution presented in Diaz-Gimenez, Quadrini and Rios-Rull (1997), about $24 \%$ of the sample belongs to the same interval as individuals without wealth.

${ }^{18}$ The wealth level for each age is computed in three steps. First, for a given age we divide agents into three different groups by earnings ability, then we construct average wealth holdings for each group, and finally we take an average of these holdings at the beginning and the end of the period.

${ }^{19}$ The averages are taken for all individuals in a cohort including those whose parents do not die at that age.
} 
bequests receipts. Far from the retirement age and expecting future earnings to increase, they do not have any motives to save except for precautionary reasons ${ }^{20}$. Around age 3 (age 40-44) they start accumulating more wealth for retirement, and at age 6 or 7 (age 55-59 or age 60-64), depending on their earnings abilities, the asset holdings are at the peaks, which is consistent with the data ${ }^{21}$. After retirement, they start dissipating assets for consumption. People with the low earnings ability dissipate most of their assets by age 11, which indicates that most of bequests are left by those with the high earnings ability. This is reflected in Table 5 for the bequests distribution, where the Gini coefficient and the percentage of the population without leaving bequests are higher than the corresponding values for wealth of retirees.

\subsubsection{Consumption Distribution}

Table 6: Consumption Distribution[Baseline]

\begin{tabular}{||c|c||}
\hline \hline Statistics for Consumption Distr. & Baseline \\
\hline \hline Gini & 0.4003 \\
\hline Variance of log consumption & 0.4643 \\
\hline Gini for working population & 0.3989 \\
\hline Gini for retired population & 0.3994 \\
\hline \hline
\end{tabular}

Table 6 shows the statistics for the consumption distribution. The consumption inequality is much lower than the earnings and wealth inequalities. The variance of log consumption for the whole population is equal to 0.4643 , which is close to the U.S. values (between 0.4 and 0.47 ) reported in Deaton and Paxon (1994), who used the 1980-1990 versions of the Consumer Expenditure Survey (CEX).

Figure 4 displays the age-consumption profiles. The profiles reproduce the empirically observed humped shape. When individuals are very young, their profiles are quite steep, but gradually become flatter. The peaks of their consumption levels are at age 4 (age $45-49$ in real life) or age 5 (age 50-54) depending on the earnings abilities, which are earlier than the peaks of wealth accumulation. This matches the U.S. value (around age 50-55) reported in Caggetti (2000), who used the Consumer Expenditure Survey (CEX), years 1980-1995. After the peaks, consumption levels steadily decrease

\footnotetext{
${ }^{20}$ They would want to borrow if there were no borrowing constraints.

${ }^{21}$ According to the data used in Diaz-Gimenez, Quadrini and Rios-Rull (1997), the average wealth held by a household is at the peak when the head of a household is between age 56 and age 60 .
} 
with age.

\subsubsection{Aggregate variables}

Finally, Table 7 shows the statistics of the aggregate variables and the prices. The U.S. ratio of the government revenues to GDP is computed from Table 1.1 and 3.1 of National Income and Product Accounts Tables by the Bureau of Economic Analysis, U.S. Department of Commerce (2001) ${ }^{22}$, and the U.S. ratio of Social Security expenditures to GDP is taken from Appendix F of The Budget and Economic Outlook: Fiscal Years 2002-2011 by Congressional Budget Office ${ }^{23}$.

Table 7: Aggregate Variables and Prices [Baseline]

\begin{tabular}{||c|c|c||}
\hline \hline Statistics for Aggregates & Baseline & U.S. Economy \\
\hline \hline Soc. Sec./GDP & $9.34 \%$ & $7.5 \%$ \\
\hline Gov. Rev./GDP & $27.82 \%$ & $27.98 \%$ \\
\hline Bequests/Capital & 0.0932 & (n/a) \\
\hline \hline Prices & & \\
\hline \hline Yearly interest rate & $4.95 \%$ & \\
\hline After-tax yearly interest rate & $2.98 \%$ & \\
\hline \hline
\end{tabular}

The aggregate variables and the prices get close to the data in like manner. The higher ratio of social security benefits to GDP may be explained by the higher proportion of retired people in the model economy.

\subsection{Complete Annuity Market}

Now the statistics of the baseline economy are compared with the hypothetical economies to see how market incompleteness and altruism affect the distribution of wealth and consumption, and overall capital accumulation. In this subsection, comparison is made with the economy in which annuity markets are completed.

Table 8 shows the statistics for the wealth distribution of this economy in comparison to those for the baseline economy. The Gini coefficients for the whole population, for each age group, and for each

\footnotetext{
${ }^{22}$ The number is the average of the current government revenues as percentage of GDP for the years $1980-1999$.

${ }^{23}$ The number is the sum of Social Security; Medicare and other federal retirement and disability programs' expenses as a percentage of GDP for the years 1980-1999.
} 
Table 8: Wealth Distribution [Complete Annuity]

\begin{tabular}{||c|c|c||}
\hline \hline Statistics for Wealth Distribution & Annuity & Baseline \\
\hline \hline Gini for the whole population & 0.8274 & 0.7810 \\
\hline Proportion of pop. without wealth & $23.98 \%$ & $20.71 \%$ \\
\hline Share of wealth held by top 1\% & $33.80 \%$ & $24.17 \%$ \\
\hline Top 5\% & $59.68 \%$ & $49.78 \%$ \\
\hline Top 10\% & $71.95 \%$ & $64.34 \%$ \\
\hline Top 20\% & $84.94 \%$ & $80.22 \%$ \\
\hline Top 40\% & $95.96 \%$ & $94.47 \%$ \\
\hline Top 60\% & $99.53 \%$ & $99.2 \%$ \\
\hline Mean/Median & 6.29 & 4.13 \\
\hline Highest 1\%/Lowest 40\% & 2894 & 1207 \\
\hline Gini for working population & 0.8412 & 0.7992 \\
\hline Proportion of working pop. w/o wealth & $28.41 \%$ & $24.83 \%$ \\
\hline Gini for retired population & 0.7861 & 0.7383 \\
\hline Proportion of retired pop. w/o wealth & $13.82 \%$ & $11.3 \%$ \\
\hline Gini for college graduates & 0.7777 & 0.7356 \\
\hline Gini for non-college graduates & 0.8024 & 0.7411 \\
\hline \hline
\end{tabular}

Table 9: Bequests Distribution [Complete Annuity]

\begin{tabular}{||c|c|c||}
\hline \hline Statistics for Bequests Distribution & Annuity & Baseline \\
\hline \hline Gini & 0.8616 & 0.8289 \\
\hline Proportion of population without bequests & $36.93 \%$ & $37.11 \%$ \\
\hline \hline
\end{tabular}

education group all increase dramatically. The hikes are caused by the concentration of wealth in rich households, as can been seen from the massive increases in the share of wealth held by top $1 \%$ of the distribution and the ratio of wealth held by top $1 \%$ to that held by bottom $40 \%$ of the distribution. In contrast, the proportions of people without wealth for the whole population and for each age group increase more modestly.

Table 10: Consumption Distribution [Complete Annuity]

\begin{tabular}{||c|c|c||}
\hline \hline Statistics for Consumption Distr. & Annuity & Baseline \\
\hline \hline Gini & 0.4178 & 0.4003 \\
\hline Variance of log consumption & 0.4918 & 0.4643 \\
\hline Gini for working population & 0.4146 & 0.3989 \\
\hline Gini for retired population & 0.4264 & 0.3994 \\
\hline \hline
\end{tabular}


Table 11: Aggregate Variables and Prices [Complete Annuity]

\begin{tabular}{||c|c|c||}
\hline \hline Statistics for Aggregates & Annuity & Baseline \\
\hline \hline Capital relative to Baseline & 0.921 & 1.00 \\
\hline Bequests relative to Baseline & 0.675 & 1.00 \\
\hline Soc. Sec./GDP & $9.33 \%$ & $9.34 \%$ \\
\hline Gov. Rev./GDP & $28.21 \%$ & $27.82 \%$ \\
\hline Bequests/Capital & 0.0683 & 0.0932 \\
\hline \hline Prices & & \\
\hline \hline Yearly interest rate & $5.45 \%$ & $4.95 \%$ \\
\hline After-tax yearly interest rate & $3.28 \%$ & $2.98 \%$ \\
\hline \hline
\end{tabular}

Figure 5 shows the age-wealth profiles for people who are in the top $20 \%$, middle $40 \%$, and bottom $40 \%$ of the earnings ability $(\theta)$ distribution. The profiles before retirement (age 7 ) have similar shapes to those of the baseline economy, although wealth accumulated before retirement is slightly lower than in the baseline economy. A notable difference is observed for the profiles after retirement, now they dissipate their assets more slowly and therefore hold more assets until their death. In the baseline economy, where there is no insurance for uncertain lifetime, people tend to spend their income for consumption while their death probabilities are relatively small, because they face the risk of leaving wealth not intended for their children at death. Now that they are insured against such events, they can smooth consumption after retirement. The fraction of assets annuitized is almost close to 1 for those in the bottom $60 \%$ of the distribution of earnings ability (when they have positive wealth), and is much lower (about 0.74 ) for those in the top $10 \%$ of the distribution. As a result, the Gini coefficient of the bequests distribution is much higher than in the baseline economy (Table 9). This would be the main reason of the higher concentration of wealth in the rich population observed in Table 8 .

As a result of higher wealth inequality, consumption inequality also becomes higher than in the baseline economy (see Table 10). The age-consumption profiles (Figure 6) show clearly the effect of complete annuity markets on consumption smoothing after retirement. The effect is particularly strong for consumption behaviors of the rich people.

Finally, Table 11 presents aggregate variables and prices. The equilibrium yearly before-tax interest rate increases to $5.45 \%$ from $4.95 \%$ of the baseline economy, which corresponds to a $7.9 \%$ decrease in aggregate capital. The lack of accidental bequests is causing this drop. Aggregate bequests show a much bigger 32.5\% decline, and as a result, the ratio of bequests to total capital drops from 0.0932 to 


\subsection{No Earnings Shock}

Table 12: Earnings Distribution [No Earnings Uncertainty]

\begin{tabular}{||c|c|c|}
\hline \hline Statistics for Earnings Distribution & No Earnings Shock & Baseline \\
\hline \hline Gini coefficient & 0.5629 & 0.6319 \\
\hline Share of earnings held by top 1\% & $6.84 \%$ & $10.26 \%$ \\
\hline Top 5\% & $23.72 \%$ & $29.19 \%$ \\
\hline Top 10\% & $37.35 \%$ & $43.34 \%$ \\
\hline Top 20\% & $55.25 \%$ & $63.2 \%$ \\
\hline Top 40\% & $80.91 \%$ & $85.38 \%$ \\
\hline Top 60\% & $95.08 \%$ & $97.19 \%$ \\
\hline Ratio of highest 1\% to lowest 40\% & 55.63 & 146.1 \\
\hline Mean/Median & 1.335 & 1.768 \\
\hline Gini for log-lifetime earnings & 0.3341 & 0.3996 \\
\hline Gini for college graduates & 0.5085 & 0.5934 \\
\hline Gini for non-college graduates & 0.4821 & 0.5763 \\
\hline Earnings ratio of college to non-college & 2.715 & 2.713 \\
\hline \hline
\end{tabular}

Table 13: Wealth Distribution [No Earnings Uncertainty]

\begin{tabular}{||c|c|c||}
\hline \hline Statistics for Wealth Distribution & No Earnings Shock & Baseline \\
\hline \hline Gini for the whole population & 0.7471 & 0.7810 \\
\hline Proportion of pop. without wealth & $26.57 \%$ & $20.71 \%$ \\
\hline Share of wealth held by top 1\% & $24.9 \%$ & $24.17 \%$ \\
\hline Top 5\% & $45.63 \%$ & $49.78 \%$ \\
\hline Top 10\% & $59.43 \%$ & $64.34 \%$ \\
\hline Top 20\% & $75.54 \%$ & $80.22 \%$ \\
\hline Top 40\% & $92.34 \%$ & $94.47 \%$ \\
\hline Top 60\% & $99.06 \%$ & $99.2 \%$ \\
\hline Mean/Median & 2.746 & 4.134 \\
\hline Highest 1\%/Lowest 40\% & 1065 & 1207 \\
\hline Gini for working population & 0.788 & 0.7992 \\
\hline Proportion of working pop. w/o wealth & $37.55 \%$ & $24.83 \%$ \\
\hline Gini for retired population & 0.6508 & 0.7383 \\
\hline Proportion of retired pop. w/o wealth & $1.44 \%$ & $11.3 \%$ \\
\hline Gini for college graduates & 0.7007 & 0.7356 \\
\hline Gini for non-college graduates & 0.7032 & 0.7411 \\
\hline \hline
\end{tabular}

In this experiment, earnings uncertainty is removed by assigning the same value of the earnings shock $\eta$ to all the individuals. The constant value of $\eta$ is set so that aggregate efficiency labor of this economy is at the same level as in the baseline economy. This economy can be considered to approximate a hypothetical economy where there exists complete insurance for earnings uncertainty.

As Table 12 shows, the earnings inequality decreases dramatically in this economy in almost all 
the dimensions, in particular a drop of the Gini for log-lifetime earnings is worth mentioning. The exception is the earnings ratio of college graduates to the rest of the population, which is expected because the distribution of the earnings ability $\theta$ is kept constant.

This large decrease in earnings inequality also greatly diminishes wealth inequality, as can be seen in Table 13. However, the effect on the working population and on the retired population are different. The Gini for the working population decreases only slightly and the proportion of households in this group without wealth increases greatly, while both the Gini and the proportion of non-wealth households for the retired population decreases dramatically. Removal of earnings uncertainty implies lower lifetime earnings inequality and smaller precautionary savings among the young, each of which affects the wealth distribution of this sub population in the opposite directions. In contrast, for retirees both the equalized lifetime earnings distribution and the resulting more equal social security benefits contribute to lower wealth inequality. Since wealth is held mostly by retirees but non-wealth households are mostly young, the overall Gini rises and the proportion of the whole population without wealth falls. The effect on the bequests distribution is similar to that on the wealth distribution of retirees as shown in Table 14.

Table 14: Bequests Distribution [No Earnings Uncertainty]

\begin{tabular}{||c|c|c||}
\hline \hline Statistics for Bequests Distribution & No Earnings Shock & Baseline \\
\hline \hline Gini & 0.7776 & 0.8289 \\
\hline Proportion of population w/o bequests & $26.06 \%$ & $37.11 \%$ \\
\hline \hline
\end{tabular}

The age-wealth profiles (Figure 7) exhibit much lower wealth accumulation before middle ages, driven by the much lower precautionary savings. After around age 4 (age $45-49$ in real life), other savings motives seem to dominate and the profiles look very similar to the baseline economy.

Table 15: Consumption Distribution [No Earnings Uncertainty]

\begin{tabular}{||c|c|c||}
\hline \hline Statistics for Consumption Distr. & No Earnings Shock & Baseline \\
\hline \hline Gini & 0.3534 & 0.4003 \\
\hline Variance of log consumption & 0.3392 & 0.4643 \\
\hline Gini for working population & 0.3499 & 0.3989 \\
\hline Gini for retired population & 0.3599 & 0.3994 \\
\hline \hline
\end{tabular}

Consumption inequality decreases greatly too (Table 15), reflecting the lower inequalities of lifetime earnings and bequests. The shapes of the age-consumption profiles (Figure 8) show a noticeable 
Table 16: Aggregate Variables and Prices [No Earnings Uncertainty]

\begin{tabular}{||c|c|c||}
\hline \hline Statistics for Aggregates & No Earnings Shock & Baseline \\
\hline \hline Capital relative to Baseline & 0.933 & 1.00 \\
\hline Bequests relative to Baseline & 1.00 & 1.00 \\
\hline Soc. Sec./GDP & $8.65 \%$ & $9.34 \%$ \\
\hline Gov. Rev./GDP & $28.16 \%$ & $27.82 \%$ \\
\hline Bequests/Capital & 0.1004 & 0.0932 \\
\hline Prices & & \\
\hline Pearly interest rate & $5.41 \%$ & $4.95 \%$ \\
\hline After-tax yearly interest rate & $3.26 \%$ & $2.98 \%$ \\
\hline \hline
\end{tabular}

difference in consumption behaviors after age 3 , in particular for the rich. In the baseline economy, after the peaks around age 4 or 5 , consumption steadily decreases with age. In contrast, in this economy, consumption is almost constant between age 3 and 7 and after age 8 it decreases more rapidly. Due to the disappearance of earnings fluctuations, they can smooth consumption during a working period to a larger degree.

Aggregate variables and prices are shown in Table 16. The yearly before-tax interest rate increases to $5.41 \%$, which implies that aggregate capital decreases by $6.7 \%$ in comparison to the baseline economy. The effect of fully insuring earnings uncertainty on aggregate capital accumulation is a little weaker than the effect of fully insuring lifetime uncertainty. The differences of the effects are more striking in bequests, now aggregate bequests are almost the same as in the baseline economy. While the lack of earnings uncertainty reduces precautionary savings greatly, the resulting decrease in inequality of lifetime earnings makes it for more people to leave bequests. These two effects on aggregate bequests seem to cancel out each other.

\subsection{No Altruism}

Finally, the effect of altruism on savings and consumption decisions are investigated by simulating the hypothetical economy where people do not obtain utility from leaving bequests. This case differs from the baseline economy only in the absence of the utility from bequests, $F\left(b^{\prime}\right)$. Accidental bequests are transferred to heirs as before.

Table 17 shows the statistics for the wealth distribution of this economy in comparison to those for the baseline economy. Inequality declines in all the dimensions. In particular, concentration of wealth 
Table 17: Wealth Distribution [No Altruism]

\begin{tabular}{||c|c|c||}
\hline \hline Statistics for Wealth Distribution & No Altruism & Baseline \\
\hline \hline Gini for the whole population & 0.7282 & 0.781 \\
\hline Proportion of pop. without wealth & $19.79 \%$ & $20.71 \%$ \\
\hline Share of wealth held by top 1\% & $14.39 \%$ & $24.17 \%$ \\
\hline Top 5\% & $38.47 \%$ & $49.78 \%$ \\
\hline Top 10\% & $55.01 \%$ & $64.34 \%$ \\
\hline Top 20\% & $74.51 \%$ & $80.22 \%$ \\
\hline Top 40\% & $92.66 \%$ & $94.47 \%$ \\
\hline Top 60\% & $98.86 \%$ & $99.2 \%$ \\
\hline Mean/Median & 3.319 & 4.134 \\
\hline Highest 1\%/Lowest 40\% & 505.2 & 1207 \\
\hline Gini for working population & 0.7608 & 0.7992 \\
\hline Proportion of working pop. w/o wealth & $24.16 \%$ & $24.83 \%$ \\
\hline Gini for retired population & 0.6525 & 0.7383 \\
\hline Proportion of retired pop. w/o wealth & $9.81 \%$ & $11.3 \%$ \\
\hline Gini for college graduates & 0.6703 & 0.7356 \\
\hline Gini for non-college graduates & 0.6973 & 0.7411 \\
\hline \hline
\end{tabular}

Table 18: Bequests Distribution [No Altruism]

\begin{tabular}{||c|c|c||}
\hline \hline Statistics for Bequests Distribution & No Altruism & Baseline \\
\hline \hline Gini & 0.7484 & 0.8289 \\
\hline Proportion of population without bequests & $34.55 \%$ & $37.11 \%$ \\
\hline \hline
\end{tabular}

in the far right tail of the distribution and the inequality of wealth among the retired population decrease greatly, reflecting the disappearance of altruism. In contrast, improvement of the wealth distribution among the working population is more modest.

Figure 9 presents the age-wealth profiles for people who are in the top $20 \%$, middle $40 \%$, and bottom $40 \%$ of the earnings ability $(\theta)$ distribution. For those with a lower earnings ability, the shape of the profile is very similar to the profile for the baseline economy. But for those with a high earnings ability, large differences are observed. First, the amount of assets accumulated at the peak (age 7) is much lower than that of the baseline economy. Further, they deplete their wealth holdings much more rapidly after the peak, and at age 11 the differences in wealth holdings among different skill groups become very small. In this economy, people are concerned only about their own consumption. While death probabilities are small, they keep large wealth for future consumption, but as the death probabilities increase with age, they decrease their assets holdings rapidly. This is the reason why the profile is much steeper for rich people after retirement, and wealth is much less concentrated in the rich. 
Table 19: Consumption Distribution [No Altruism]

\begin{tabular}{||c|c|c||}
\hline \hline Statistics for Consumption Distr. & No Altruism & Baseline \\
\hline \hline Gini & 0.3938 & 0.4003 \\
\hline Variance of log consumption & 0.4631 & 0.4643 \\
\hline Gini for working population & 0.3951 & 0.3989 \\
\hline Gini for retired population & 0.388 & 0.3994 \\
\hline \hline
\end{tabular}

Table 20: Aggregate Variables and Prices [No Altruism]

\begin{tabular}{||c|c|c||}
\hline \hline Statistics for Aggregates & No Altruism & Baseline \\
\hline \hline Capital relative to Baseline & 0.796 & 1.00 \\
\hline Bequests relative to Baseline & 0.667 & 1.00 \\
\hline Soc. Sec./GDP & $9.35 \%$ & $9.34 \%$ \\
\hline Gov. Rev./GDP & $29.0 \%$ & $27.82 \%$ \\
\hline Bequests/Capital & 0.0781 & 0.0932 \\
\hline \hline Prices & & \\
\hline \hline Yearly interest rate & $6.48 \%$ & $4.95 \%$ \\
\hline After-tax yearly interest rate & $3.90 \%$ & $2.98 \%$ \\
\hline \hline
\end{tabular}

Figure 10 shows the age-bequests receipts profiles for young adults. Now all the bequests are accidental as opposed to those altruistically motivated. The biggest difference from the baseline economy is the huge drop in the amount of bequests received after age 3. At age 6 nobody receives any bequests. As they get older, death probabilities of their parents become higher, and as a result, the parents reduce their assets holdings. When the parents are at age 11, they know that they are going to die for certain, so they do not leave any bequests. Table 18 shows the distribution of bequests. The Gini coefficient is much lower smaller the baseline economy and the proportion of population without leaving bequests is a little lower.

The lower wealth inequality also results in lower consumption inequality, as observed in Table 19, but the decrease is very small, especially for the working population and for the whole population. More equal bequests receipts tend to equalize the consumption distribution among the young, while the disappearance of altruism allows richer people to consumer more, and the result suggests that the two effects nearly cancel out each other. Figure 11 shows that the age-consumption profile for people with a high-earnings ability is much steeper after retirement compared to the baseline economy, which corresponds to the rapid dissipation of wealth holdings seen in the age-wealth profile (Figure 9).

Finally, Table 20 presents aggregate variables and prices. The equilibrium yearly before-tax interest rate increases to $6.48 \%$ from $4.95 \%$, associated with a $20.4 \%$ decrease in aggregate capital. The 
disappearance of altruism in this economy also results in a $33.3 \%$ decrease in aggregate bequests.

\subsection{Robustness}

The above results have been based on the calibration where the correlation coefficient of the AR(1) process for the earnings shock, $\zeta$, is set 0.4 and the coefficient of relative risk aversion $\sigma$ is 4.0 . Although this calibration has produced good matches of the model economy to the U.S. economy, there are no U.S. statistics that directly pin down the values of these two parameters. Since they are crucial in determining the relative strength of the precautionary motive of savings, this section checks robustness of the results by choosing different values for the two parameters and recalibrating the model accordingly.

\subsubsection{Comparisons of baseline economies under different parameterization}

Table 21: Calibrated Bequest Parameters

\begin{tabular}{||c||c|c|c||}
\hline \hline & $\sigma=3.0$ & $\sigma=4.0$ & $\sigma=5.0$ \\
\hline \hline$\zeta=0.3$ & $b_{1}=-0.4$ & $b_{1}=-0.215$ & $b_{1}=-0.17$ \\
$\sigma_{\varepsilon}^{2}=0.4079$ & $b_{2}=24$ & $b_{2}=21$ & $b_{2}=18$ \\
\hline$\zeta=0.4$ & $b_{1}=-0.365$ & $b_{1}=-0.175$ & $b_{1}=-0.15$ \\
$\sigma_{\varepsilon}^{2}=0.392$ & $b_{2}=18$ & $b_{2}=19$ & $b_{2}=17$ \\
\hline$\zeta=0.5$ & $b_{1}=-0.28$ & $b_{1}=-0.16$ & $b_{1}=-0.14$ \\
$\sigma_{\varepsilon}^{2}=0.3704$ & $b_{2}=17$ & $b_{2}=14$ & $b_{2}=13$ \\
\hline \hline
\end{tabular}

Table 22: Earnings Distribution when $\zeta=0.3,0.4$, and 0.5

\begin{tabular}{||c|c|c|c||}
\hline \hline Statistics for Earnings Distribution & $\zeta=0.3$ & $\zeta=0.4$ & $\zeta=0.5$ \\
\hline \hline$\sigma_{\varepsilon}^{2}$ & 0.4079 & 0.392 & 0.3704 \\
\hline Gini of lifetime earnings & 0.3943 & 0.3996 & 0.4058 \\
\hline 5 year correlation of log earnings & 0.682 & 0.7203 & 0.7581 \\
\hline Intergenerational correlation of log-lifetime earnings & 0.4623 & 0.4484 & 0.4322 \\
\hline \hline
\end{tabular}

The procedure of the recalibration is as follows. For the parameter $\zeta$, three different values $0.3,0.4$, and 0.5 are tried. For a given value of $\zeta$, the variance of the disturbance term to the earnings shock process, $\sigma_{\varepsilon}^{2}$, is adjusted so that the cross-sectional distribution of earnings remains unchanged. As for the coefficient of relative risk aversion $\sigma$, the values 3.0,4.0, and 5.0 are tried. For a given value of $\sigma$, the parameters of the bequest function $b_{1}$ and $b_{2}$ are adjusted so that the baseline model under the new parameterization yields the same Gini coefficient for the wealth distribution of the whole 
Table 23: Wealth, Bequests, and Consumption Distributions for different values of $\zeta$ when $\sigma=4.0$

\begin{tabular}{||c|c|c|c||}
\hline Statistics & $\zeta=0.3$ & $\zeta=0.4$ & $\zeta=0.5$ \\
\hline \hline Share of wealth held by top 1\% & $24.32 \%$ & $24.17 \%$ & $22.85 \%$ \\
\hline Wealth ratio of top 1\% to bottom 40\% & 1092.4 & 1206.9 & 1613.8 \\
\hline Wealth Gini for working population & 0.7985 & 0.7992 & 0.8015 \\
\hline Proportion of working pop. w/o wealth & $23.29 \%$ & $24.83 \%$ & $26.89 \%$ \\
\hline Wealth Gini for retired population & 0.7395 & 0.7383 & 0.7339 \\
\hline Proportion of retired pop. w/o wealth & $10.32 \%$ & $11.3 \%$ & $13.59 \%$ \\
\hline Bequests Gini & 0.8303 & 0.8289 & 0.8211 \\
\hline Consumption Gini & 0.3934 & 0.4003 & 0.4047 \\
\hline Bequests/Capital & 0.0962 & 0.0932 & 0.0907 \\
\hline \hline
\end{tabular}

Table 24: Wealth, Bequests, and Consumption Distributions for different values of $\sigma$ when $\zeta=0.4$

\begin{tabular}{||c|c|c|c||}
\hline \hline Statistics & $\sigma=3.0$ & $\sigma=4.0$ & $\sigma=5.0$ \\
\hline \hline Share of wealth held by top 5\% & $48.39 \%$ & $49.78 \%$ & $50.66 \%$ \\
\hline Wealth ratio of top 1\% to bottom 40\% & 1755.5 & 1206.9 & 893.4 \\
\hline Wealth Gini for working population & 0.8033 & 0.7992 & 0.796 \\
\hline Proportion of working pop. w/o wealth & $30.02 \%$ & $24.83 \%$ & $23.76 \%$ \\
\hline Wealth Gini for retired population & 0.7301 & 0.7383 & 0.7458 \\
\hline Proportion of retired pop. w/o wealth & $12.48 \%$ & $11.3 \%$ & $9.97 \%$ \\
\hline Bequests Gini & 0.8246 & 0.8289 & 0.8307 \\
\hline Consumption Gini & 0.4079 & 0.4003 & 0.3882 \\
\hline Bequests/Capital & 0.0884 & 0.0932 & 0.0965 \\
\hline \hline
\end{tabular}

population. Note that this does not mean that other dimensions of the wealth distribution remain unchanged with the new parameters. Table 21 shows the chosen values of the bequest parameters for 9 combinations of $\zeta$ and $\sigma$, including the original parameterization, $\zeta=0.4$ and $\sigma=4.0$.

Table 22 presents selected statistics of the earnings distributions when the correlation coefficient of the earnings shock process, $\zeta$, is set $0.3,0.4$, and 0.5 . Since the unconditional distribution of the earnings shock is kept constant, the distributions of earnings for the whole population and for each skill group do not change. In contrast, the distribution of lifetime earnings becomes more unequal with larger $\zeta$, since the earnings shock at age 0 is drawn from the same unconditional distribution but it becomes more crucial in determining the shocks at later ages. Obviously the period-by-period correlation of log earnings increases and the intergenerational correlation of log-lifetime earnings decrease with larger $\zeta$.

Selected statistics of the distributions of wealth, bequests, and consumption for different values of $\zeta$ when $\sigma=4.0$ are summarized in Table 23. Similar qualitative results are found for $\sigma=3.0$ and 5.0 as well. Other things being equal, higher persistence of the earnings shocks (larger $\zeta$ ) increases inequality of lifetime earnings and decreases precautionary savings by the young, both contributing 
to higher wealth inequality among them ${ }^{24}$. As seen in the previous section, savings for bequests are not important in determining their saving behaviors, so the distribution of wealth of the working population becomes more unequal with larger $\zeta$. Thus, in order to keep the Gini for the whole population constant, wealth inequality among the retirees must be decreased slightly. This is achieved by weakening altruistically motivated savings through lowering bequest parameters $b_{1}$ and $b_{2}$ when $\zeta$ is higher. Higher inequality in lifetime earnings also raises consumption inequality slightly. Because of the lower values of the bequest parameters, the ratio of aggregate bequests to aggregate capital declines.

Table 24 shows selected statistics of the distributions of wealth, bequests, and consumption for different values of $\sigma$ when $\zeta$ is set 0.4. Qualitative results remain unchanged when $\zeta=0.3$ and 0.5. Other things being equal, the higher value for the coefficient of relative risk aversion increases precautionary savings and total capital accumulation and reduces wealth inequality among the working population. In order to keep the Gini for the whole population constant across different calibrations, therefore, wealth inequality among the retired population needs to be raised slightly. Note that higher $\sigma$ also implies a lower rate of intertemporal substitution, thus a flatter age-consumption profile. Since consumption is at peak before retirement, savings for consumption after retirement increase, which contributes to higher wealth inequality among the retired population ${ }^{25}$ and larger wealth accumulation. As a result of this larger wealth accumulation, the interest rate declines and the relative return from leaving bequests goes up for given bequests parameters, which raises altruistically motivated savings and wealth inequality among the retirees even more. It turns out that, in order to match the Gini for the whole population, bequest parameters must be smaller when $\sigma$ is higher. Because of stronger precautionary motives, proportions of the population without wealth decrease. The ratio of bequests to capital increases due to higher life-cycle savings.

\footnotetext{
${ }^{24}$ Precautionary savings are relatively more important among the poor, who leave little bequests and receive social security benefits more than proportional to earnings.

${ }^{25}$ This is due to the presence of progressive social security system.
} 


\subsubsection{Robustness of results on distributions}

Changes in the distributions of wealth, bequests, and consumption, and aggregate variables in the three hypothetical economies in comparison to the baseline economy are qualitatively the same in almost all the dimensions under all the parameterization. Quantitatively, as detailed below, differences in rates of the changes are observed.

E'conomy with complete annuity markets: In all the nine cases, almost all the measures of inequalities worsen and aggregate capital and bequests decrease in this economy compared to the baseline economy. When the coefficient of relative risk aversion $\sigma$ is larger, rates of increases in wealth inequality and of a decrease in capital become smaller, while the rate of a decrease in bequests becomes larger. On the other hand, raising the correlation coefficient of the earnings shock process $\zeta$ has mostly ambiguous effects on the rates of changes of distribution measures, but it does increase the rates of the decreases of bequests and capital accumulation. When the coefficient is higher, the calibrated bequests parameters are smaller and altruism is relatively weaker (the ratio of bequests to capital is smaller), hence the change is larger.

Economy without earnings uncertainty: In the economy without earnings uncertainty, the proportion of households without wealth goes up except for the retired population, and all the other measures of wealth inequality, consumption inequality, and aggregate capital accumulation fall for all the parameter values. In contrast, the effect on aggregate bequests is ambiguous. Higher $\sigma$ implies smaller rates of decreases of the inequality measures except proportions of households without wealth. The rates of increases of the proportions and decreases of aggregate capital, in turn, increase with larger $\sigma$. Increasing $\zeta$ raises rates of decreases of inequality measures aside from proportions of people without wealth (except for the retired population), whose rates of increases fall. The effect on rates of changes on capital and bequests are ambiguous.

Economy without altruism: In all the cases, wealth and bequests inequalities and aggregate capital and bequests decline in contrast to the baseline economy. In contrast, the effect on consumption inequality is ambiguous, declining when $\sigma=3.0$ and 4.0 but rising when $\sigma=5.0$, and rates of the changes are very small. Rates of decreases of wealth and bequests inequalities and of the aggregate variables are larger when the coefficient of relative risk aversion $\sigma$ is higher, except for proportions 
Table 25: Capital and Bequests [Complete Annuity]

\begin{tabular}{||c||c|c|c||}
\hline \hline & $\sigma=3.0$ & $\sigma=4.0$ & $\sigma=5.0$ \\
\hline \hline$\zeta=0.3$ & capital: 0.99 & capital: 0.925 & capital: 0.928 \\
$\sigma_{\varepsilon}^{2}=0.4079$ & bequests: 0.723 & bequests: 0.695 & bequests: 0.743 \\
\hline$\zeta=0.4$ & capital: 0.9519 & capital: 0.921 & capital: 0.908 \\
$\sigma_{\varepsilon}^{2}=0.392$ & bequests: 0.651 & bequests: 0.675 & bequests: 0.712 \\
\hline$\zeta=0.5$ & capital: 0.929 & capital: 0.884 & capital: 0.878 \\
$\sigma_{\varepsilon}^{2}=0.3704$ & bequests: 0.577 & bequests: 0.602 & bequests: 0.648 \\
\hline \hline
\end{tabular}

Table 26: Capital and Bequests [No Earnings Shock]

\begin{tabular}{||c||c|c|c||}
\hline \hline & $\sigma=3.0$ & $\sigma=4.0$ & $\sigma=5.0$ \\
\hline \hline$\zeta=0.3$ & capital: 0.929 & capital: 0.9333 & capital: 0.898 \\
$\sigma_{\varepsilon}^{2}=0.4079$ & bequests: 0.981 & bequests: 1.017 & bequests: 0.979 \\
\hline$\zeta=0.4$ & capital: 0.9523 & capital: 0.9327 & capital: 0.903 \\
$\sigma_{\varepsilon}^{2}=0.392$ & bequests: 1.009 & bequests: 1.004 & bequests: 0.986 \\
\hline$\zeta=0.5$ & capital: 0.962 & capital: 0.919 & capital: 0.896 \\
$\sigma_{\varepsilon}^{2}=0.3704$ & bequests: 0.999 & bequests: 0.983 & bequests: 0.975 \\
\hline \hline
\end{tabular}

of households without wealth or bequests. Rate of their declines are greater when the correlation coefficient of the earnings shock process $\zeta$ is smaller.

\subsubsection{Robustness of results on aggregate capital and bequests accumulation}

Finally, robustness is checked with respect to rates of changes in aggregate capital and bequests of the three hypothetical economies in comparison to the baseline economy. Table 25 presents aggregate capital and bequests in the economy with complete annuity markets in all the nine cases. As before, the values are normalized so that capital and bequests in the baseline economy is equal to 1 for each parameterization. In all the cases, both capital and bequests decrease with the latter decreasing more. The decreases are greater when the correlation coefficient of the earnings shock process $\zeta$ is larger. As for the coefficient of relative risk aversion $\sigma$, the decrease in capital is greater and the decrease in bequests is smaller when the coefficient is higher, except for one case. The rate of capital decline ranges from $1.0 \%$, when $\sigma=3.0$ and $\zeta=0.3$, to $12.2 \%$, when $\sigma=5.0$ and $\zeta=0.5$, while the rate of bequests decline ranges from $25.7 \%$, when $\sigma=5.0$, and $\zeta=0.3$ to $42.3 \%$, when $\sigma=3.0$ and $\zeta=0.5$.

Table 26 shows capital and bequests in the economy without earnings uncertainty. Aggregate capital decline in all the cases, while bequests decrease in six cases and increase in three cases. Capital decreases more and bequests are more likely to decline when $\sigma$ is greater except for one case. As for $\zeta$, 
Table 27: Capital and Bequests [No Altruism]

\begin{tabular}{||c||c|c|c||}
\hline \hline & $\sigma=3.0$ & $\sigma=4.0$ & $\sigma=5.0$ \\
\hline \hline$\zeta=0.3$ & capital: 0.841 & capital: 0.759 & capital: 0.700 \\
$\sigma_{\varepsilon}^{2}=0.4079$ & bequests: 0.717 & bequests: 0.617 & bequests: 0.549 \\
\hline$\zeta=0.4$ & capital: 0.865 & capital: 0.796 & capital: 0.726 \\
$\sigma_{\varepsilon}^{2}=0.392$ & bequests: 0.756 & bequests: 0.667 & bequests: 0.586 \\
\hline$\zeta=0.5$ & capital: 0.901 & capital: 0.836 & capital: 0.761 \\
$\sigma_{\varepsilon}^{2}=0.3704$ & bequests: 0.815 & bequests: 0.726 & bequests: 0.628 \\
\hline \hline
\end{tabular}

there are no such clear-cut tendency. The rate of capital decline ranges from $3.8 \%$, when $\sigma=3.0$ and $\zeta=0.5$, to $10.4 \%$, when $\sigma=5.0$ and $\zeta=0.5$, while the rate of bequests decline ranges from $-1.7 \%$, when $\sigma=4.0$ and $\zeta=0.3$, to $2.5 \%$, when $\sigma=5.0$ and $\zeta=0.5$.

Lastly Table 27 presents capital and bequests in the economy without altruism. Under every parameterization both capital and bequests decline greatly, and the declines are larger when $\sigma$ is larger and $\zeta$ is smaller. The rate of capital decline ranges from $9.9 \%$, when $\sigma=3.0$ and $\zeta=0.5$, to $30.0 \%$, when $\sigma=5.0$ and $\zeta=0.3$, while the rate of bequests decline ranges from $18.5 \%$, when $\sigma=3.0$ and $\zeta=0.5$, to $45.1 \%$, when $\sigma=5.0$ and $\zeta=0.3$.

Comparisons of the three hypothetical economies show that capital decline is always largest in the economy without altruism and bequests decline is always smallest in the economy without earnings uncertainty. Other rankings depend on parameter values, but in 6 out of the 9 cases, capital decline is larger in the economy with complete annuity markets than in the economy without earnings uncertainty, and again in 6 out of the 9 cases, bequests decline is larger in the economy without altruism than in the economy with complete annuity markets. Differences in rates of changes of aggregate capital among the three economies are smallest when $\sigma=3.0$ and $\zeta=0.5$ and largest when $\sigma=5.0$ and $\zeta=0.3$, while differences in rates of changes of bequests are smallest when $\sigma=3.0$ and $\zeta=0.3$ and largest when $\sigma=5.0$ and $\zeta=0.3$ or when $\sigma=3.0$ and $\zeta=0.5$.

\section{Conclusions}

This paper has investigated quantitative importance of different savings motives on wealth distribution and aggregate capital accumulation by solving an overlapping generations model with heterogeneity within generations. Agents differ in age, ability, earnings shocks and inherited bequests. In the 
baseline economy there are uninsurable idiosyncratic risks associated with uncertain lifetime and earnings shocks. The model's parameter values have been chosen so that the simulated earnings and wealth distributions of the baseline economy match those observed in the U.S. data.

We have compared the allocations of the baseline economy with those of an economy with complete annuity markets, an economy without earnings uncertainty, and an economy without altruism. The numerical experiments have shown that different savings motives seem to affect savings behaviors of various parts of the population in an unequal manner, so their effects on wealth distribution and capital accumulation are distinctive. The effect of completing annuity markets is dominantly on the old population and results in a large increase in wealth and bequests inequality through higher concentration of assets in the upper tail of the distribution. This is obtained because poor people try to annuitize most of their wealth if annuity securities are available. Alternatively, taking out earnings uncertainty decreases savings by the young population, especially among the poor, but lowers wealth inequality for the whole population because of the equalized lifetime earnings. Finally, the disappearance of altruism affects mainly savings behavior of the old and rich population, reducing wealth and bequests inequality by lowering the concentration of wealth in the upper tail of the distribution.

The comparisons of aggregate capital and bequests in the three hypothetical economies with those in the baseline economy suggest that, aside from the pure life-cycle motive of savings, altruism is the most important factor affecting aggregate capital and bequests accumulation. Secondly in order of importance, especially in explaining aggregate bequests, is the absence of annuity markets that generate precautionary savings among the retired population and accidental bequests. The absence of insurance markets for earnings uncertainty, which generates precautionary savings among the working population, seems to be least important, in particular, in explaining bequests accumulation.

\section{References}

[1] Ando, Albert, and Arthur B. Kennickell, "How Much (or Little) Life Cycle Is There in Micro Data? The Cases of the United States and Japan," In Dornbusch, Rudiger, Stanley Fischer, and John Bossons eds., Macroeconomics and finance: Essays in honor of Franco Modigliani, 
Cambridge, Mass. and London: MIT Press, 1987.

[2] Attanasio, O.P., and M. Browning, "Consumption over the Life Cycle and over the Business Cycle," American Economic Review 85 (5), 1118-1137, 1995.

[3] Auerbach, A.J. and Laurence J. Kotlikoff, Dynamic Fiscal Policy, New York: Cambridge University Press, 1987.

[4] Barro, Robert J., "Are Government Bonds Net Wealth?," Journal of Political Economy 82 (6), 1095-1130, November/December 1974.

[5] Becker, Gary S., "A Theory of Social Interactions," Journal of Political Economy 82 (6), 10631094, November/December 1974.

[6] Blinder, Alan, "Life Cycle Saving vs. Intergenerational Transfers: Comments," In Kessler, Denis and Andre Masson eds., Modelling the Accumulation and Distribution of Wealth. Oxford; New York; Toronto and Melbourne: Oxford University Press, Clarendon Press, 1988.

[7] Bureau of Economic Analysis, U.S. Department of Commerce, National Income and Product Accounts Tables, 2001.

[8] Caballero, R.J., "Earnings Uncertainty and Aggregate Wealth Accumulation," American Economic Review 81, 859-871, 1991.

[9] Cagetti, M., "Wealth Accumulation over the Life Cycle and Precautionary Savings," mimeo, University of Chicago, 2000.

[10] Caroll, C.D., "Buffer-stock Saving and the Life Cycle/Permanent Income Hypothesis," Quarterly Journal of Economics, 112, 1-55, 1997.

[11] Castaneda, Ana, Javier Diaz-Gimenez, and Castaneda, Diaz-Gimenez, and Jose Victor Rios-Rull, "Accounting for Earnings and Wealth Inequality," mimeo, 2000.

[12] Congressional Budget Office, The Long-Term Budget Outlook, October 2000.

[13] Deaton, A., "Saving and Liquidity Constraints," Econometrica 59, 1221-1248, 1991. 
[14] Deaton, A., Understanding Consumption, Oxford: Oxford University Press, 1992.

[15] Deaton, A. and C. Paxsọn, "Intertemporal Choice and Inequality," Journal of Political Economy, $102,437-467,1994$.

[16] De Nardi, Cristina, "Wealth Inequality and Intergenerational Links," Federal Reserve Bank of Chicago Working Paper, no. 13, September 1999.

[17] Diaz-Gimenez, Javier, Vicenzo Quadrini, and Jose Victor Rios-Rull, "Dimension of Inequality : Facts on the U.S. Distributions of Earnings, Income and Wealth," Federal Reserve of Minneapolis Quarterly Review 21 (2), 3-21, Spring 1997.

[18] French, Eric, "The Labor Supply Response to (Mismeasured but) Predictable Wage Changes," Federal Reserve Bank of Chicago, WP-2000-08.

[19] Gale William G. and John K. Scholz, "Intergenerational transfers and the Accumulation of Wealth," Journal of Economic Perspectives 8 (4), 145-160, Autumn 1994.

[20] Gokhale, Jagadeesh, Laurence J.Kotlikoff, James Sefton, Martin Weale, "Simulating the Transmission of Wealth Inequality via Bequests," Journal of Public Economics 79(1), 93-128, January 2001.

[21] Gourinchas, P-O and J. A. Parker, "Consumption over the Life Cycle", E'conometrica 70(1),47-89, January 2002.

[22] Hubbard, R.G., J.S. Skinner and S.P. Zeldes, "The Importance of Precautionary Motives in Explaining Individual and Aggregate Saving," Carnegie-Rochester Conference Series on Public Policy 40, 59-125, 1994.

[23] Hubbard, R.G., J.S. Skinner and S.P. Zeldes, "Precautionary Saving and Social Insurance," Journal of Political Economy 103(2), 360-399, 1995.

[24] Hurd, Micheal D., "Mortality Risk and Bequests," Économetrica 57 (4), 779-813, July 1989. 
[25] Hurd, Micheal D.A. and B.G. Mundaca, "The Importance of Gifts and Inheritancs among the Affluent," in Lipsey, Robert E. and Helen Stone Tice, eds., The Measurement of Saving, Investment and Wealth, Chicago: University of Chicago Press, 737-58, 1989.

[26] Kessler, Denis and Andre Masson, "Bequest and Wealth Accumulation: Are Some Pieces of the Puzzle Missing?," Journal of Economic Perspectives 3 (3), 141-152, Summer 1989.

[27] Kotlikoff, Laurence J. and Avia Spivak, "The Family as an Incomplete Annuities Market," Journal of Political Economy 89 (2), 372-391, April 1981.

[28] Kotlikoff, Laurence J. and Lawrence H. Summers, "The Role of Intergenerational Transfers in Aggregate Capital Accumulation," Journal of Political Economy 89 (4), 706-732, August 1981.

[29] Kotlikoff, Laurence J., "Intergenerational Transfers and Savings," Journal of Economic Perspectives 2 (2), 41-48, Spring 1988.

[30] Laitner, John, "Random Earnings Differences, Lifetime Liquidity Constraints, and Altruistic Intergenerational Transfers," Journal of Economic Theory 58(2), 135-70, December 1992.

[31] Laitner, John, "Wealth Inequality and Estate Taxation," mimeo, Octorber 2000.

[32] Lord, William and Peter Ranzagas, "Savings and Wealth in Models with Altruistic Bequests," American Economic Review, 81, 289-96, March 1991.

[33] Mason, Andre, "A Cohort Analysis of Age-Wealth Profiles Generated by a Simulated Model in France (1949-1975)," E'conomic Journal, 96 , 173-90, March 1986.

[34] Mendoza, Enrique G., Assaf Razin, and Linda L. Tesar, "Effective Tax Rates in Macroeconomics: Cross-Country Estimates of Tax Rates on Factor Incomes and Consumption," Journal of Monetary Economics 34(3), 297-323, December 1994.

[35] Modigliani, Franco, "The Role of Intergenerational Transfers and Life Cycle Saving in the Accumulation of Wealth," Journal of Economic Perspectives, 2 (2), 15-40, Spring 1988. 
[36] Mulligan, Casey B., Parental Priorities and Economic Inequality, Chicago and London: University of Chicago Press, 1997.

[37] Quadrini, Vicenzo and Jose Victor Rios-Rull, "Understanding the U.S. distribution of Wealth," Federal Reserve Bank of Minneapolis Quarterly Review, 21 (2), 22-36, Spring 1997.

[38] Solon, Gary, "Intergenerational Income Mobility in the United States," American Economic Review 82 (3), 393-408, June 1992.

[39] Tauchen, George, "Finite State Markov-Chain Approximations to Univariate and Vector Autoregressions," E'conomic Letters 20, 177-181, 1986.

[40] U.S. Department of Health and Human Services, Center for Disease Control and prevention, National Center for Health Statistics, National Vital Statistics Reports, December 1999.

[41] Yaari, Menachem H., "Uncertain Lifetime, Life Insurance, and the Theory of the Consumer," Review of Economic Studies, 32 (2),137-150, April 1965.

[42] Zimmerman, David J., "Regression toward Mediocrity in Economic Stature," American Economic Review 82(3), 409-29, 1992.

\section{Appendix : Computational Algorithms}

\subsection{Algorithm to compute the steady-state distribution}

Step 1: Enter the $j$ th iteration with a guess for the real interest rate $r^{j}$, and the wage rate $w^{j}$. Also set the interval for assets to be $\left[0, a_{\max }\right]$.

Step 2 (Solving the Dynamic Programming Problem): Solve the problem backwards starting from the problem at age 11 .

2-1 (Old Adult's Problem): Given the prices, solve the old adult's maximization problem (22) at age 11 and obtain the value function $J^{11}(\bar{l}, a ; S)$ and the corresponding decision rules. Given the value function at age $11, J^{11}(\bar{l}, a ; S)$, solve the old adult's maximization problem (22) at age 10 and obtain the value function $J^{10}(\vec{l}, a ; S)$ and the corresponding decision rules. Continuing in this way, 
solve the maximization problems up to age 7 . The solution of the problem at age 7 gives the value function $J^{7}(\bar{l}, a ; S)$ and the associated decision rules.

\section{2-2 (Problem at age 6):}

a) (When the parent died before the previous period): Given the value function at age $7, J^{7}(\bar{l}, a ; S)$, solve the maximization problem (20) and obtain the value function $W^{6}(\theta, \eta, \bar{l}, a ; S)$ and the associated decision rules.

b) (When the parent has just died): Given the value function, solve the maximization problem (21) and obtain the value function $\tilde{V}^{6}\left(\theta, \eta, \bar{l}, a, s^{p} ; S\right)$ and the decision rules.

\section{2-3 (Young Adult's Problem):}

a) (When the parent died before the previous period): Given $W^{j+1}(\theta, \eta, \bar{l}, a ; S)(1 \leq j \leq 5)$, solve the problem (19) and obtain $W^{j}(\theta, \eta, \bar{l}, a ; S)$ and the corresponding decision rules.

b) (When the parent has just died): Given $W^{j+1}(\theta, \eta, \bar{l}, a ; S)(0 \leq j \leq 5)$, solve the problem (17) and obtain $\widetilde{V}^{j}\left(\theta, \eta, \bar{l}, a, s^{p} ; S\right)$ and the decision rules.

c) (When the parent is alive): Given $\widetilde{V}^{j+1}\left(\theta, \eta, \bar{l}, a, s^{p} ; S\right)(0 \leq j \leq 5)$ and $V^{j+1}\left(\theta, \eta, \bar{l}, a, s^{p} ; S\right)$ $(0 \leq j \leq 4)$, solve the problem (9) and obtain $V^{j}\left(\theta, \eta, \bar{l}, a, s^{p} ; S\right)$ and the decision rules.

Step 3 (Monte Carlo Simulation): Pick an initial child-parent pair, who are at age 0 and age 6 , respectively. Starting from this pair, perform a Monte Carlo simulation for one lineage based on the decision rules computed above. Continue the simulation for large enough numbers of generations. Based on the simulation, obtain the distribution of assets and efficiency labor. Since the model has an ergodic property, the computed distribution remains the same if the simulation is performed for many different lineages. See the next subsection for detailed procedures.

Step 4 (Adjustment of the interval of assets): Check if the distribution of assets does not have a large mass at the maximum level of assets, $a_{\max }$. If it has, increase the value of $a_{\max }$ and resolve the maximization problems and redo the Monte Carlo simulation (Go back to Step 2).

Step 5 (Update of the prices and the convergence check ): Based on the distributions of the state variables, compute aggregate capital $\mathbf{k}^{j}$ and efficiency labor $\mathbf{l}^{j}$. Substituting these values into the firm's first-order conditions, obtain the implied real interest rate $r^{j}$ and wage rate $w^{j}$. Stop if the price differences from the last iteration are small enough. If not, go back to Step 1 with new 
guesses for the prices. For the updated prices, the weighted averages of the currently used prices and the newly computed prices might be used.

\subsection{Monte Carlo Simulation}

Step 1 (Initial states of the initial child-parent pair): Start the simulation with the initial childparent pair, whose ages are age 0 and age 6 , respectively. Their initial states must be determined.

Assume that the parent of the age 6 adult's parent is dead before the previous period. Then the age 6 adult's state variables are the only information needed to solve his maximization problem (20). His initial assets level $a_{-1}^{6}$ and average labor productivity $\bar{l}_{-1}^{6}$ are set arbitrary ${ }^{26}$, and the variables $\theta_{-1}$ and $\eta_{-1}^{6}$ are drawn randomly from the underlying (unconditional) distributions . Based on the initial state variables, the decision rules for his current consumption and assets holdings in the next period $a_{-1}^{7}$, and the transition rules for his state variables are determined.

The state variables of the young adult are the ones needed to solve the problem (9). His initial asset level $a_{0}^{0}$ is set to be zero, the variables $\theta_{0}$ and $\eta_{0}^{0}$ are drawn randomly from the underlying (unconditional) distributions, and the average labor productivity $\bar{l}_{0}^{0}$ is set to be $\theta_{0} \eta_{0}^{0} \phi(0)$. Since he is assumed to make decisions after observing his parent's decisions, his remaining state variables (the parental state) are the age of his parent $(=6), \bar{l}_{-1}^{6}$, and $a_{-1}^{7}$. The parental state is needed to predict possible bequests receipt. Based on the initial state variables, the decision rules for his consumption and assets $a_{0}^{1}$, and the transition rules for the states are determined.

Step 2 (Determination of the initial old adult's living status): Since the old adult faces a positive death probability, his living status for the next period must be determined. His living status is determined based on the survival probability. If he dies when turning age 7 , the amount of bequests left to the young adult is equal to $a_{-1}^{7}$.

Step 3 (Initial young adult before age 6): One period has passed. If the old adult is still alive, he solves the same maximization problem as in the previous period. Given his current states $\bar{l}_{-1}^{7}$ and $a_{-1}^{7}$, the decision rules and the transition rules for his states are determined.

If the old parent is still alive, the young adult solves the same problem as in the previous period.

\footnotetext{
${ }^{26}$ The subscript is an index for generation and the superscript is an index for age. The generation who is at age 0 in the initial period is denoted generation 0 , and the generation of age 6 (his parent) is denoted generation -1 .
} 
If not, he receives bequests equal to $a_{-1}^{7}$ and solves the problem (17). The value of $v_{0}^{1}$ is drawn randomly from the underlying unconditional distribution, which together with the stochastic process (13) determines $\eta_{0}^{1}$. His new average labor productivity $\bar{l}_{0}^{1}$ is determined based on (12). The other state variables are determined as in the previous period. Based on his states, the decision rules and the transition rules for the states are determined. A similar process is continued until the young adult becomes age 6 .

Step 4 (Initial young adult after age 6 and his child): Now the young adult is at age 6 . At this age, he has his child (age 0) and his parent is already dead. He solves the problem (20) if his parent died before this period and solves the problem (21) if his parent has just died. His child's initial state variables must be set. The initial value for assets $a_{2}^{0}$ is zero, the variable $\eta_{2}^{0}$ is drawn randomly from the underlying unconditional distribution, and the initial ability $\theta_{2}^{0}$ must be determined based on the parent's ability $\theta_{1}^{0}$ and the stochastic process (7). The initial average labor productivity is given by $\bar{l}_{2}^{0}=\theta_{2}^{0} \phi(0) \eta_{2}^{0}$. The new age 0 individual solves the problem (9).

Step 5 (Remaining generations): Step 3 and Step 4 are repeated for a large enough number of generations, say 150,000 generations. The state variables of the first 15,000 generations are discarded in order to remove effects of initial conditions, and using the variables for the remaining generations, the distributions of the states over the population are computed. 
Figure 2: Age-Wealth Profile [Baseline]

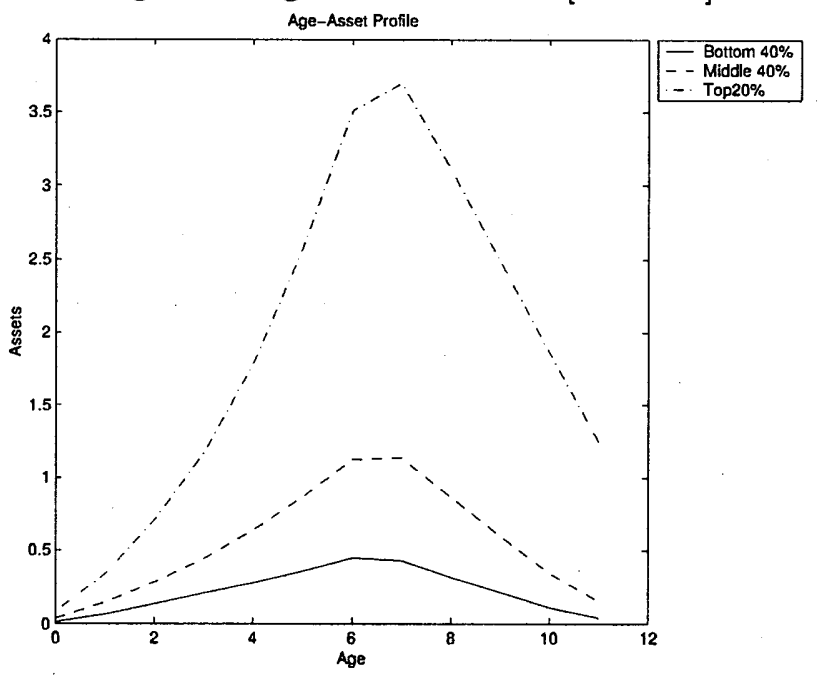

Figure 3: Age-Bequests Profile [Baseline]

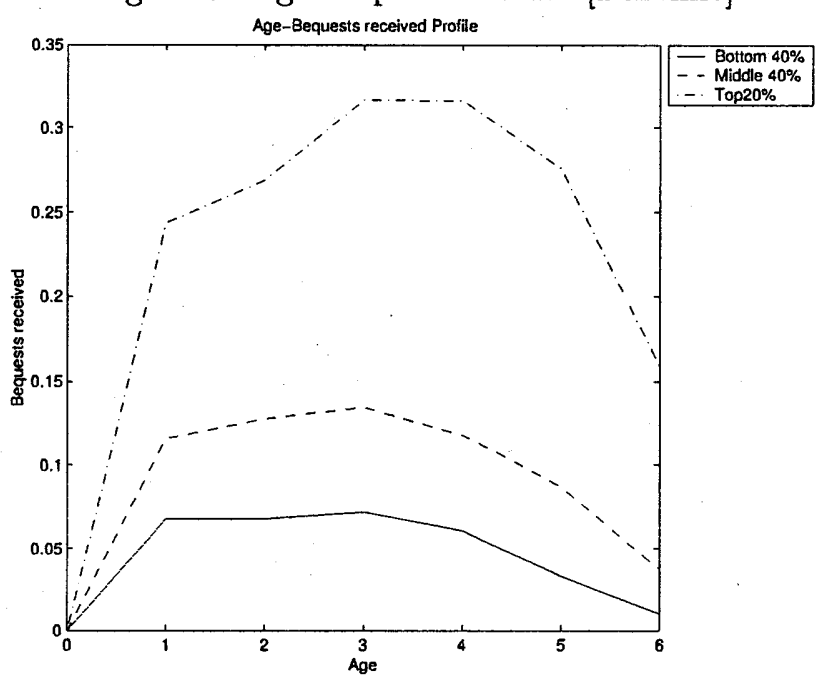


Figure 4: Age-Consumption Profile [Baseline]

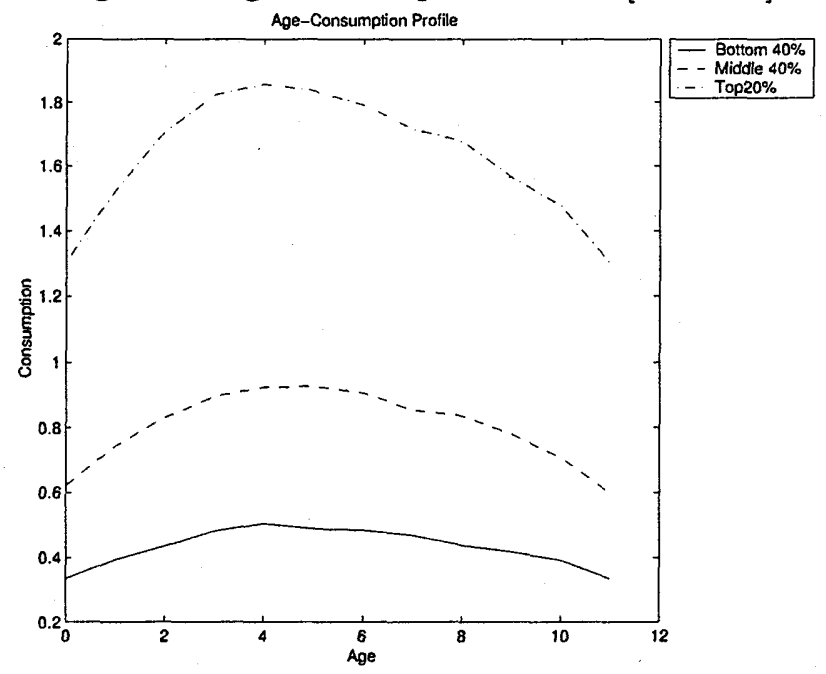

Figure 5: Age-Wealth Profile [Complete Annuity]

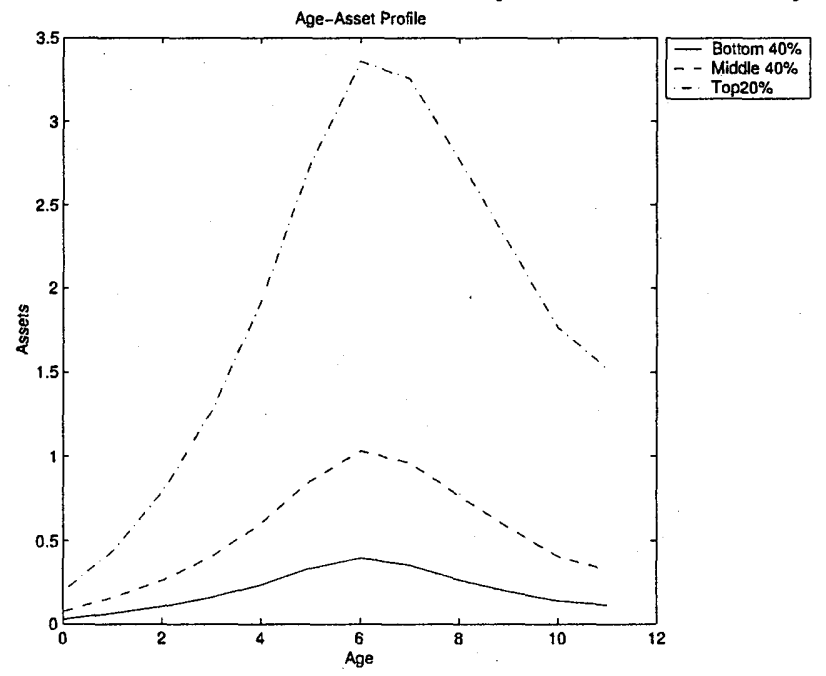


Figure 6: Age-Consumption Profile [Complete Annuity]

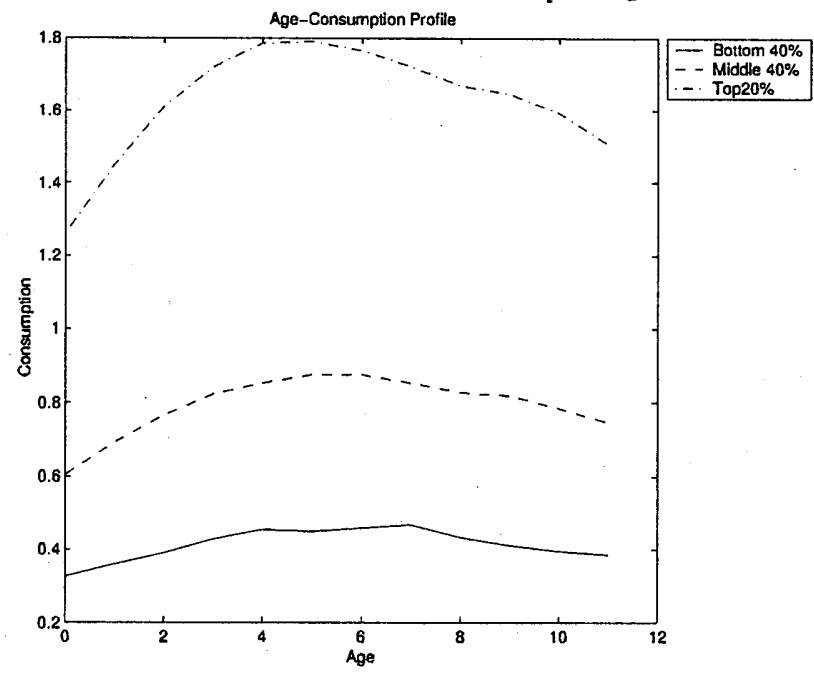

Figure 7: Age-Wealth Profile [No Earnings Uncertainty]

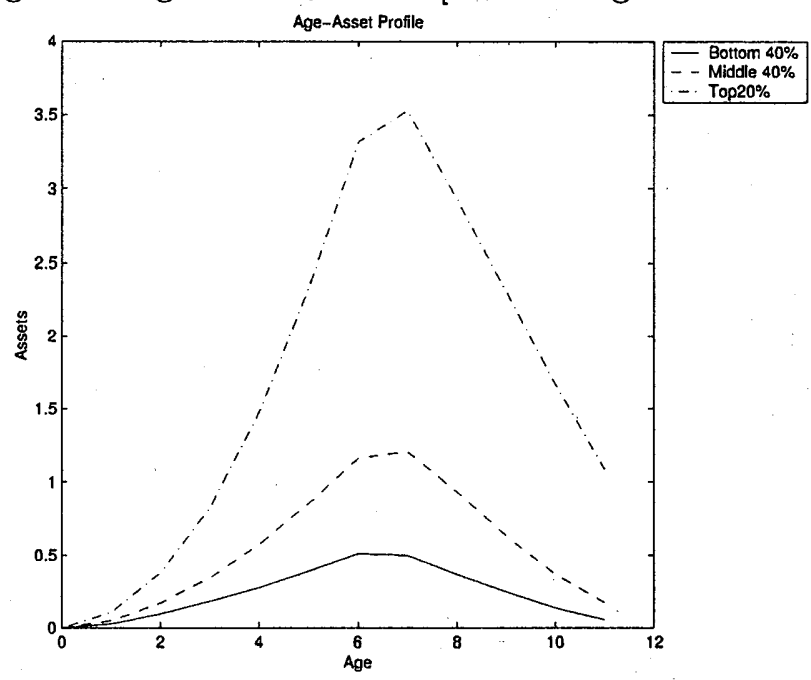


Figure 8: Age-Consumption Profile [No Earnings Uncertainty]

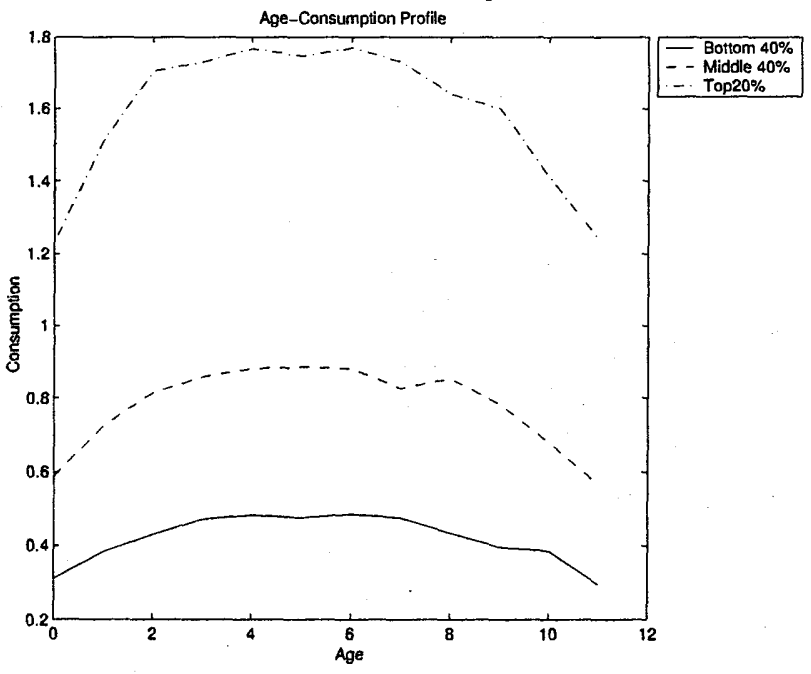

Figure 9: Age-Wealth Profile [No Altruism]

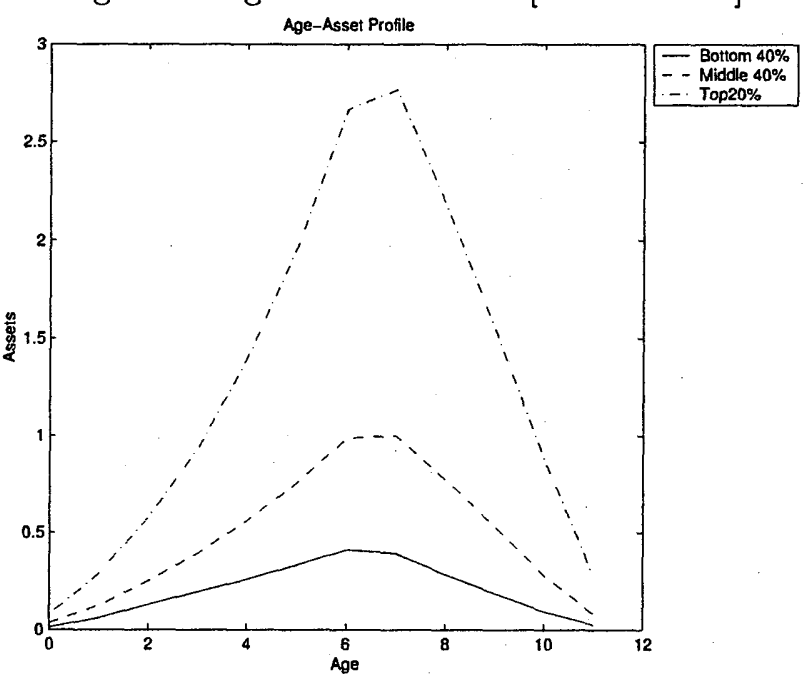




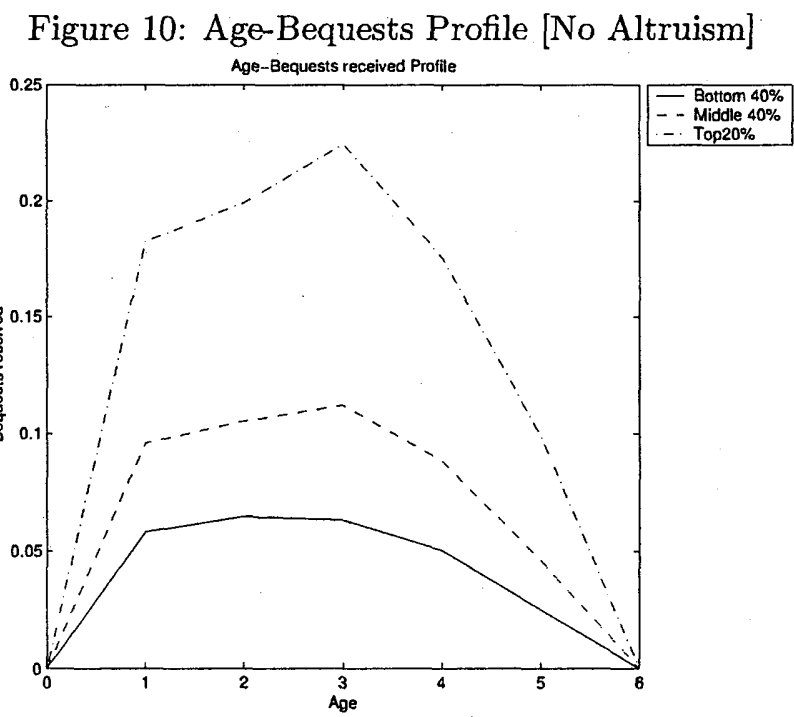

Figure 11: Age-Consumption Profile [No Altruism]

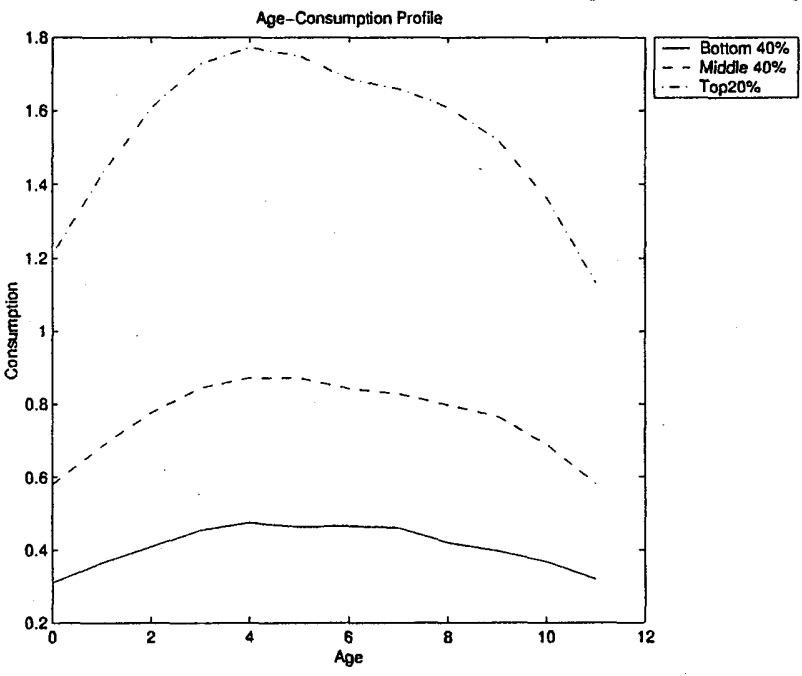

